\title{
Potential of multispectral synergism for observing ozone pollution by combining IASI-NG and UVNS measurements from the EPS-SG satellite
}

\author{
Lorenzo Costantino $^{1}$, Juan Cuesta ${ }^{1}$, Emanuele Emili ${ }^{2}$, Adriana Coman ${ }^{1}$, Gilles Foret ${ }^{1}$, Gaëlle Dufour ${ }^{1}$, \\ Maxim Eremenko $^{1}$, Yohann Chailleux ${ }^{1}$, Matthias Beekmann ${ }^{1}$, and Jean-Marie Flaud ${ }^{1}$ \\ ${ }^{1}$ Laboratoire Interuniversitaire des Systèmes Atmosphériques (LISA), CNRS UMR7583, Université Paris Est Créteil, \\ Université Paris Diderot, Créteil, France \\ ${ }^{2}$ Centre Européen de Recherche et de Formation Avancée en Calcul Scientifique (CERFACS), Toulouse, France
}

Correspondence to: Lorenzo Costantino (lore.costantino@gmail.com)

Received: 12 November 2016 - Discussion started: 21 December 2016

Revised: 27 February 2017 - Accepted: 1 March 2017 - Published: 3 April 2017

\begin{abstract}
Present and future satellite observations offer great potential for monitoring air quality on a daily and global basis. However, measurements from currently orbiting satellites do not allow a single sensor to accurately probe surface concentrations of gaseous pollutants such as tropospheric ozone. Combining information from IASI (Infrared Atmospheric Sounding Interferometer) and GOME-2 (Global Ozone Monitoring Experiment-2) respectively in the TIR and UV spectra, a recent multispectral method (referred to as IASI+GOME-2) has shown enhanced sensitivity for probing ozone in the lowermost troposphere (LMT, below $3 \mathrm{~km}$ altitude) with maximum sensitivity down to $2.20 \mathrm{~km}$ a.s.l. over land, while sensitivity for IASI or GOME-2 alone only peaks at 3 to $4 \mathrm{~km}$ at the lowest.

In this work we develop a pseudo-observation simulator and evaluate the potential of future EPS-SG (EUMETSAT Polar System - Second Generation) satellite observations, from new-generation sensors IASI-NG (Infrared Atmospheric Sounding Interferometer - New Generation) and UVNS (Ultraviolet Visible Near-infrared Shortwaveinfrared), to observe near-surface $\mathrm{O}_{3}$ through the IASING+UVNS multispectral method. The pseudo-real state of the atmosphere is provided by the MOCAGE (MOdèle de Chimie Atmosphérique à Grande Échelle) chemical transport model. We perform full and accurate forward and inverse radiative transfer calculations for a period of 4 days (8-11 July 2010) over Europe.

In the LMT, there is a remarkable agreement in the geographical distribution of $\mathrm{O}_{3}$ partial columns between
\end{abstract}

IASI-NG+UVNS pseudo-observations and the corresponding MOCAGE pseudo-reality. With respect to synthetic IASI+GOME- 2 products, IASI-NG+UVNS shows a higher correlation between pseudo-observations and pseudo-reality, which is enhanced by about $12 \%$. The bias on high ozone retrieval is reduced and the average accuracy increases by $22 \%$. The sensitivity to LMT ozone is also enhanced. On average, the degree of freedom for signal is higher by $159 \%$ over land (from 0.29 to 0.75 ) and $214 \%$ over ocean (from 0.21 to 0.66 ). The mean height of maximum sensitivity for the LMT peaks at $1.43 \mathrm{~km}$ over land and $2.02 \mathrm{~km}$ over ocean, respectively 1.03 and $1.30 \mathrm{~km}$ below that of IASI+GOME2. IASI-NG+UVNS also shows good retrieval skill in the surface $-2 \mathrm{~km}$ altitude range. It is one of a kind for retrieving ozone layers of $2-3 \mathrm{~km}$ thickness, in the first $2-3 \mathrm{~km}$ of the atmosphere. IASI-NG+UVNS is expected to largely enhance the capacity to observe ozone pollution from space.

\section{Introduction}

The retrieval of tropospheric ozone is a major issue for air quality studies. Ground-level ozone is a priority air pollutant, causing approximately 22000 excess deaths per year in Europe (Amann et al., 2005). Current (e.g. Meteorological Operational, MetOp; Earth Observing System - Aura, EOSAura) and future (e.g. EUMETSAT Polar System - Second Generation, EPS-SG; Meteosat Third Generation Sounder, 
MTG-S) satellite observation systems offer great potential for monitoring air quality on a daily and global basis. Because of their global coverage every day, they can be used in synergy with global or regional chemical transport models (CTMs) for full data assimilation (e.g. Coman et al., 2012) or intervalidation (e.g. Zyryanov et al., 2012). Recent spaceborne instruments such as the Infrared Atmospheric Sounding Interferometer IASI (Clerbaux et al., 2009) and the Global Ozone Monitoring Experiment-2 GOME-2 (EUMETSAT, 2006), both on board MetOp satellites, offer a daily global coverage that is appropriate for monitoring pollution. Their ground resolutions are relatively fine, with four $12 \mathrm{~km}$-diameter pixels spaced by $25 \mathrm{~km}$ (at nadir) for IASI and $80 \times 40 \mathrm{~km}^{2}$ ground pixels for GOME-2.

Both TIR and UV observations are able to provide vertical information on ozone concentration. UV sounders were traditionally used for the stratosphere but recently also for the troposphere (e.g. Liu et al., 2010) and TIR sensors are particularly sensitive to tropospheric ozone, down to the lower troposphere (below $6 \mathrm{~km}$ altitude; Eremenko et al., 2008). However, it has been shown that when using space-borne observations from one spectral domain (either TIR or UV), only ozone down to $3-4 \mathrm{~km}$ altitude at the lowest may be observed with adequate vertical sensitivity (Foret et al., 2014). Recent studies combine the information on ozone distribution from radiance measurements of different spectral domains to enhance sensitivity in the LMT. Numerical studies (Landgraf and Hasekamp, 2007; Worden et al., 2007) showed a significant improvement in sensitivity when retrieving ozone in the lowest $5 \mathrm{~km}$ of the troposphere, combining TIR and UV measurements respectively from TES (Tropospheric Emission Spectrometer) and OMI (Ozone Monitoring Instrument) sounders (both on board the Aura satellite).

More recently, new retrieval approaches have shown the ability to derive ozone profiles from the multispectral synergism from real TIR and UV satellite measurements. Fu et al. (2013) combined measurements from TES (for TIR) and OMI (for UV) sensors and founded a clear improvement in retrieval sensitivity and vertical resolution in the troposphere as well as a sensitivity and accuracy enhancement below $700 \mathrm{hPa}$ compared with either instrument alone. Due to the limited spatial coverage of TES (no across-track scanning is performed), this method was analysed on a profile-to-profile basis (Fu et al., 2013). Cuesta et al. (2013) developed a multispectral synergism of IASI (for TIR) and GOME-2 (for UV) spectra capable of observing the daily distribution of ozone plumes located below $3 \mathrm{~km}$ altitude from space, defined here as the lowermost troposphere (LMT). This last multispectral approach (referred to as IASI+GOME-2 and used in the following of this paper) shows a particularly good accuracy (low mean bias near 1\% and precision of $16 \%$ ) and the capacity to observe the horizontal distribution of LMT ozone provided the scanning capacities of both IASI and GOME-2. IASI+GOME-2 allows the observation of LMT ozone due to the altitude of maximum sensitivity for the LMT peaking ex-
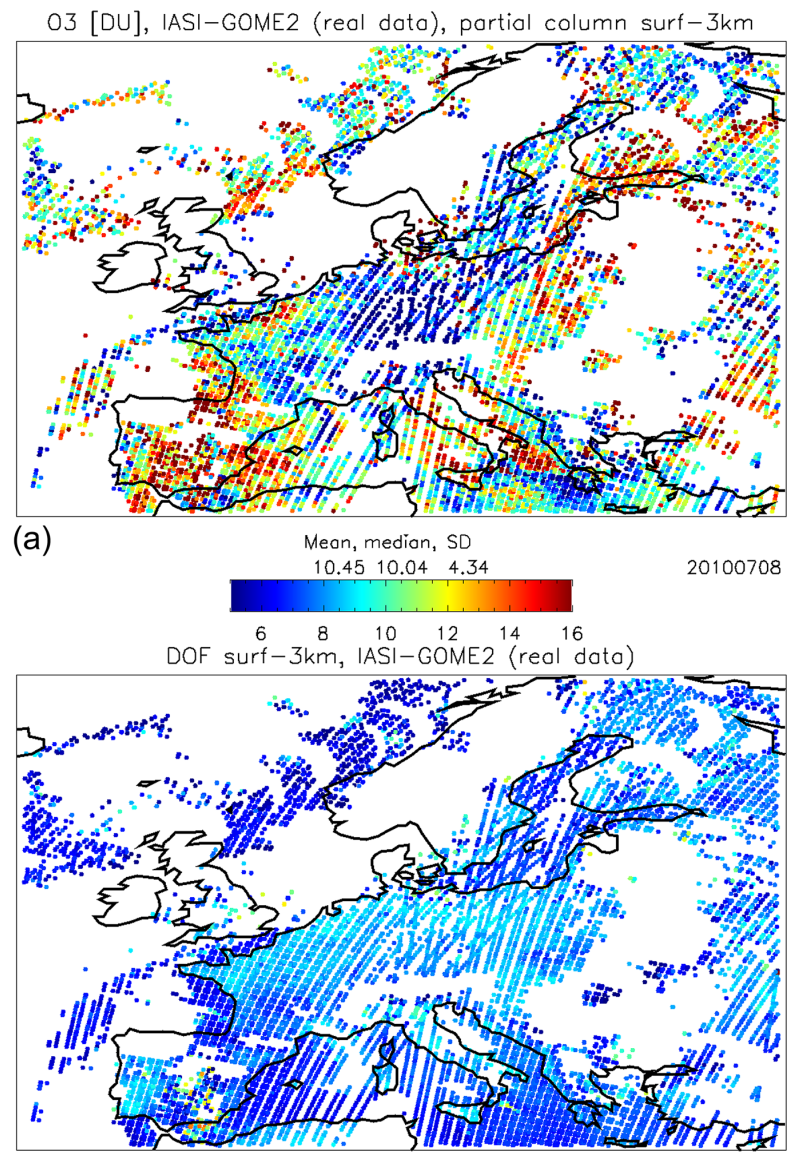

(b)

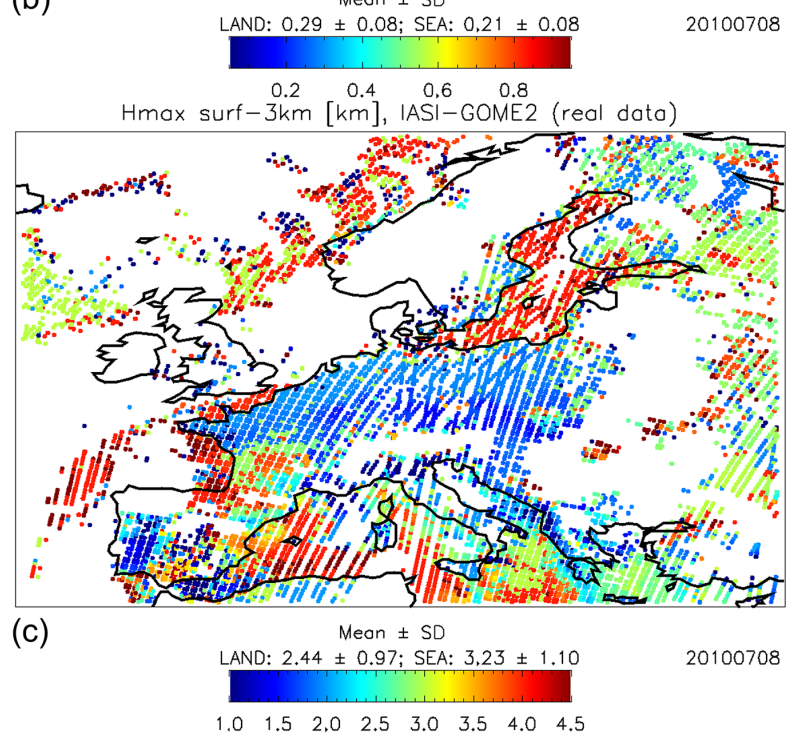

Figure 1. Real IASI+GOME-2 retrievals for 8 July 2010. Maps of ozone column density $(\mathrm{O} 3-3 \mathrm{~km})[\mathrm{DU}](\mathbf{a})$, the degree of freedom (DOF-3km) (b), and the altitude of maximum sensitivity (Hmax$3 \mathrm{~km})[\mathrm{km}]$ calculated between the surface and $3 \mathrm{~km}$ altitude (c). White areas indicate a lack of measurements due to the presence of relatively high cloud fraction ( $>30 \%$ ), unavailability of satellite data or invalid retrievals. 

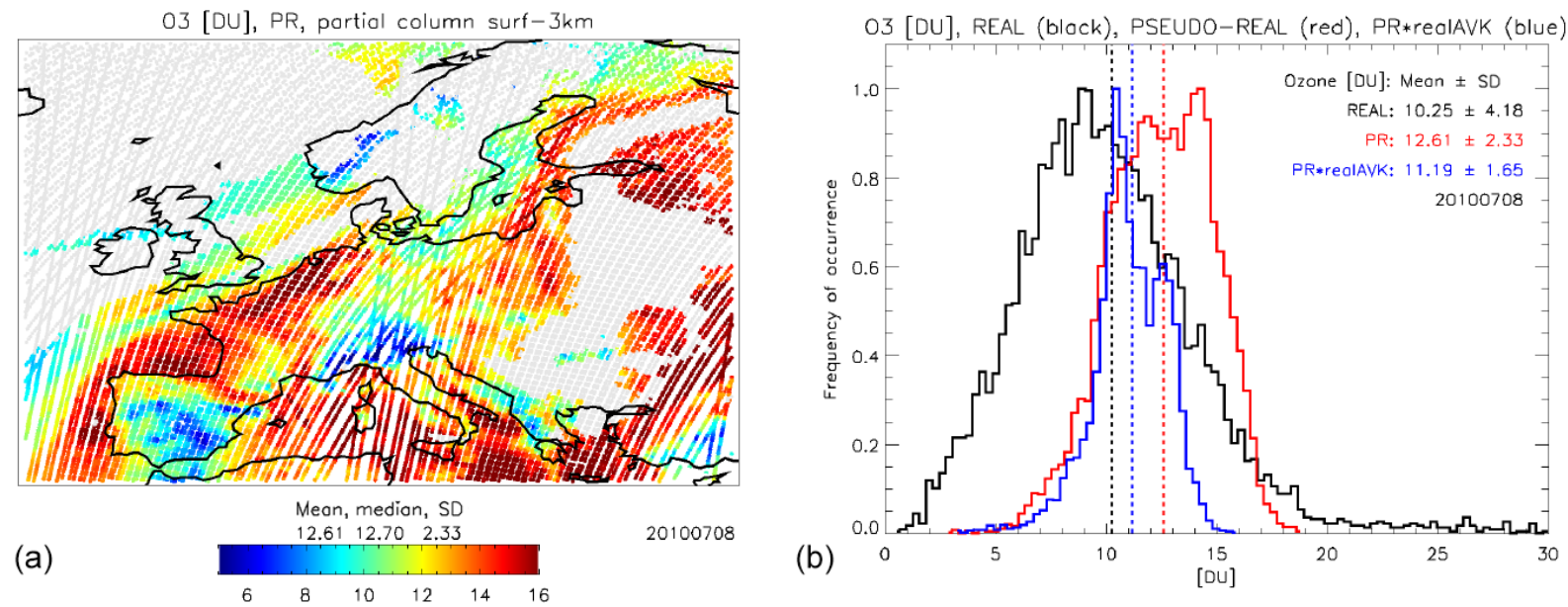

Figure 2. MOCAGE simulation for 8 July 2010. (a) Map of pseudo-real O3-3km [DU]. For consistency with Fig. 1, we consider only those MOCAGE pixels that would have been selected by the IASI+GOME-2 retrieval algorithm on that day. (b) O3-3km [DU] normalized frequency distributions from real IASI+GOME-2 measurements (black), pseudo-real MOCAGE data (red) and PR smoothed by real AVK (blue). Dashed lines show mean O3-3km [DU] values of each distribution.

ceptionally low, on average at $2.2 \mathrm{~km}$ height over land (about $800 \mathrm{~m}$ below single-band methods), enhancing the degree of freedom (for signal) in the LMT by about $40 \%$ with respect to single-band retrievals. IASI+GOME-2 uses two radiative transfer codes, KOPRA (Karlsruhe Optimized and Precise Radiative transfer Algorithm) and VLIDORT (Vector Linearized Discrete Ordinate Radiative Transfer). The inversion algorithm is integrated in the inversion module KOPRAfit. It uses a Tikhonov-Phillips-type altitude-dependent regularization that optimizes sensitivity to LMT (Eremenko et al., 2008), maximizing the degree of freedom (for signal, DOF) and minimizing the total retrieval error simultaneously.

Incoming satellite missions are expected to carry newgeneration instrumentation capable of providing more accurate observations of tropospheric composition closer to the surface. This is the case for IASI-NG (Infrared Atmospheric Sounding Interferometer - New Generation) and UVNS (Ultraviolet Visible Near-infrared Shortwave-infrared) spectrometers, both of which are on board the EPS-SG satellite which is expected to be launched in 2022 on a polar-orbit, similar to MetOp. The UVNS instrument is part of the ESA mission Sentinel-5 payload and is dedicated to monitoring the composition of the atmosphere for Copernicus Atmosphere Services.

The advent of these new-generation sensors may allow significant advances in LMT ozone sensing and air quality monitoring. This enhancement needs to be accurately quantified in order to prepare air quality monitoring systems for these future satellite products.

\section{Purpose and strategy}

The objective of this work is to provide a quantitative assessment of the potential of upcoming new-generation spacebased observing systems for monitoring ozone pollution. In particular, we investigate the performance of the multispectral synergism of IASI-NG (for TIR emitted spectra) and UVNS (for UV backscattered radiances) measurements. IASI-NG will have half of the IASI radiometric noise and a finer spectral resolution of factor 2 (see Table 1). UVNS will have a higher signal-to-noise ratio (SNR) than GOME-2 and a much finer horizontal resolution but a coarser spectral resolution of factor 2 . To estimate the performances and errors associated with IASI-NG+UVNS, we adapt the existing IASI+GOME-2 retrieval approach to the technical specifications of IASI-NG and UVNS (Table 1). Hereafter, this method will be referred to as IASI-NG+UVNS.

We set up a pseudo-observation simulator (POS) which is part of an observing system simulation experiment (OSSE). OSSEs are specific type of sensitivity analysis used to quantify the expected added value of an observing system (OS). They have been largely used to analyse the gain of future satellite missions on trace gas monitoring (Edwards et al., 2009; Claeyman et al., 2011; Zoogman et al., 2011) and are generally composed of three elements: a nature run, a pseudo-observation simulator and an assimilation run. The nature run defines the pseudo-real state of the atmosphere for the experiment (Masutani et al., 2010). The pseudoobservation simulator generates the pseudo-retrievals. It calculates and inverts the spectra as would be done by the observing system, simulating OS performances and errors. The assimilation run consists of the assimilation of pseudoretrievals into a new model simulation which is different and independent from the nature run. 

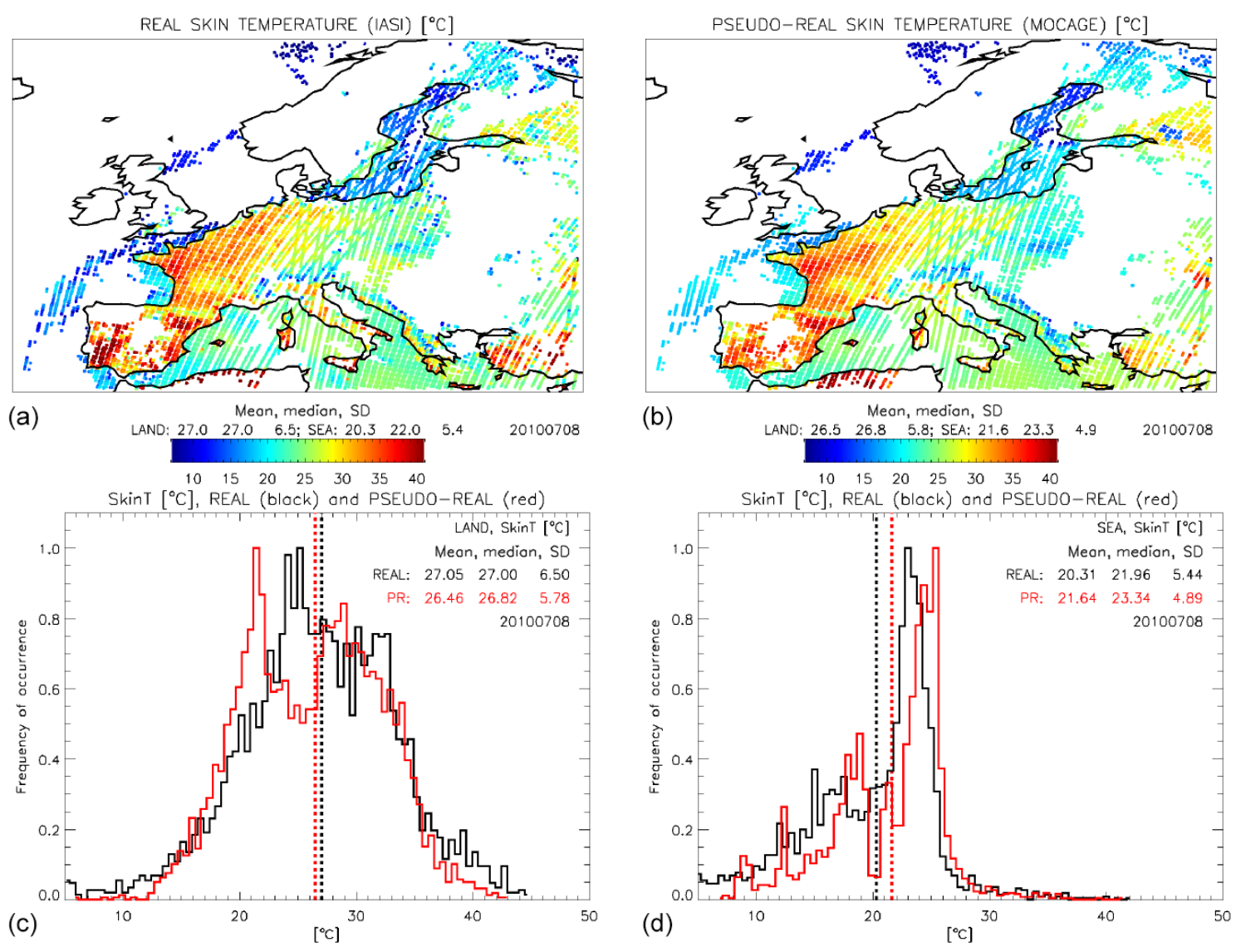

Figure 3. Maps of surface temperature, $T_{\mathrm{S}}\left[{ }^{\circ} \mathrm{C}\right]$, from real IASI measurements (a) and from the MOCAGE simulation (b) before correction, for 8 July 2010. For consistency with IASI data, we consider only those MOCAGE pixels that would have been selected by IASI+GOME-2 retrieval algorithm on that day. Histograms of $T_{\mathrm{S}}$ normalized frequency distributions from real data (IASI, black) and pseudo-real outputs (MOCAGE, red) over land (c) and ocean (d). Dashed lines indicate the mean value. We consider only those pixels with skin temperature in the $5-45^{\circ} \mathrm{C}$ range and where the absolute $T_{\mathrm{S}}$ difference between real measurements and MOCAGE is lower than $10^{\circ} \mathrm{C}$.

In this work, we only focus on the first two steps of a typical OSSE: the nature run and the simulator of synthetic retrievals, while the assimilation run is left to a further and future research effort. Pseudo-reality is generated by the chemical transport model MOCAGE (MOdèle de Chimie Atmosphérique à Grande Échelle) that simulates physical and chemical processes of atmospheric gases and aerosols including clouds (e.g. Josse et al., 2004; Marécal et al., 2015). For a practical consideration of computation, OSSEs typically approximate the pseudo-observations by means of a predefined parametrization of the averaging kernels (AVKs) that describe the retrieval method sensitivity to true vertical profiles of atmospheric species. If this procedure avoids full radiative transfer calculations and costly computational time, approximated averaging kernels with no (or limited) scenedependence may fail to replicate the variability of the full radiative transfer calculations (Sellitto et al., 2013); complex scene-dependent parametrizations of AVK (Worden et al., 2013) may represent a more useful cost-benefits compromise in the case of multispectral/multi-instrument observing systems. In order to avoid these approximations, we perform full and accurate forward and inverse radiative transfer calculations, but for a limited time period of 4 days.

We pay particular attention to setting-up and running the simulation experiment with a high degree of reliability. Indeed, systematic biases in the key parameters of the model lead to unrealistic performances of the satellite product. This is particularly true for parameters such as cloud fraction, surface temperature and temperature profiles. The consistency of pseudo-reality and POS with respect to real data and existing sensor products is analysed and validated in terms of absolute magnitude and spatial variability of a number of atmospheric variables (ozone concentration and temperature profiles, skin temperature) and diagnostic parameters (degree of freedom and altitude of maximum sensitivity of the retrieval algorithm).

In the following paragraphs, we present the methodology used to set up parts of the simulation experiment: the nature run, the forward radiative transfer calculations and retrieval scheme of the OS simulator. Then, we carry out a statisti- 

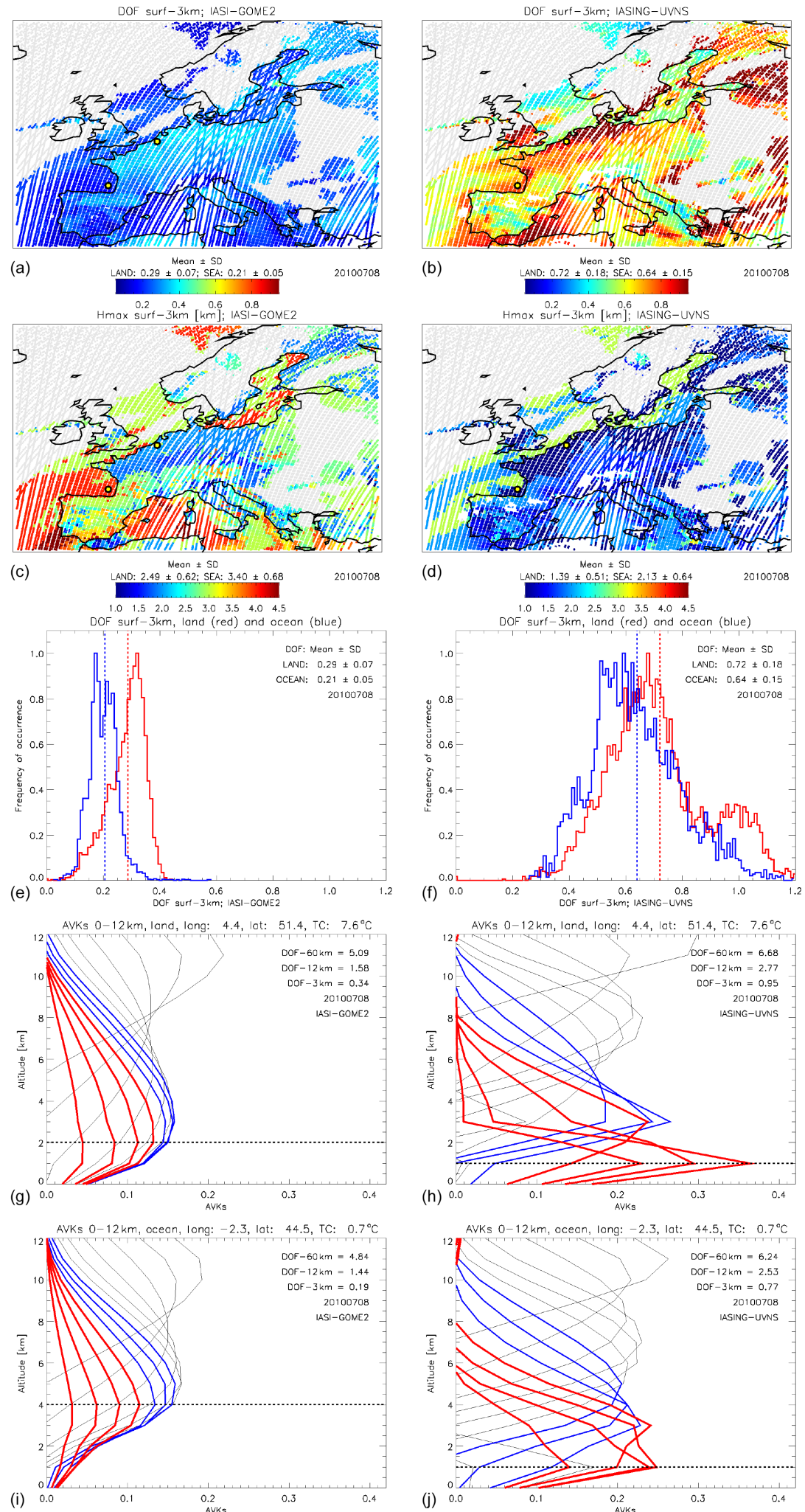

Figure 4. IASI+GOME-2 (a, c, e, g, i) and IASI-NG+UVNS (b, d, f, h, j) data, for 8 July 2010. (a, b) Maps of DOF-3km from pseudoobservations (POs), grey colour indicates where CLF is larger than 0.3. (c, d) Maps of Hmax-3km [km] from POs. (e, f) Histograms of DOF-3km normalized frequency distribution from POs over land (red) and ocean (blue). (g, h) AVK vertical profiles at retrieval altitudes of $0,1,2,3 \mathrm{~km}$ (red) and 4, 5, $6 \mathrm{~km}$ (blue) and 7, 8, 9, 10,11, $12 \mathrm{~km}$ (black) for a pixel over land (black-yellow spot in the map) in a highly polluted area. Values of DOF-60km, DOF-12km and DOF- $3 \mathrm{~km}$ are reported in the figure. Dashed line indicates the altitude of maximum sensitivity in the LMT. (i, j) Same as before but over ocean. 

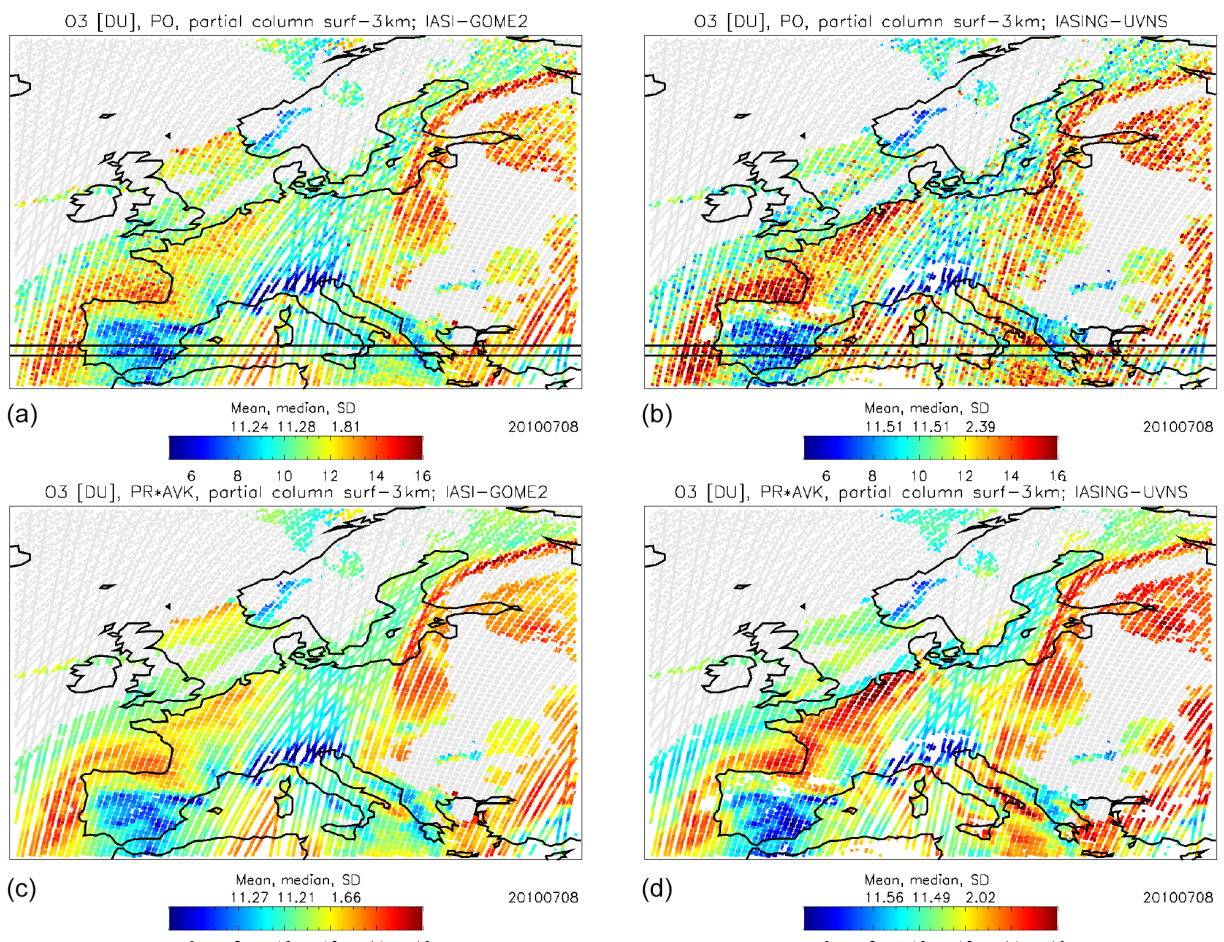

(d)

Mean, medion, SD
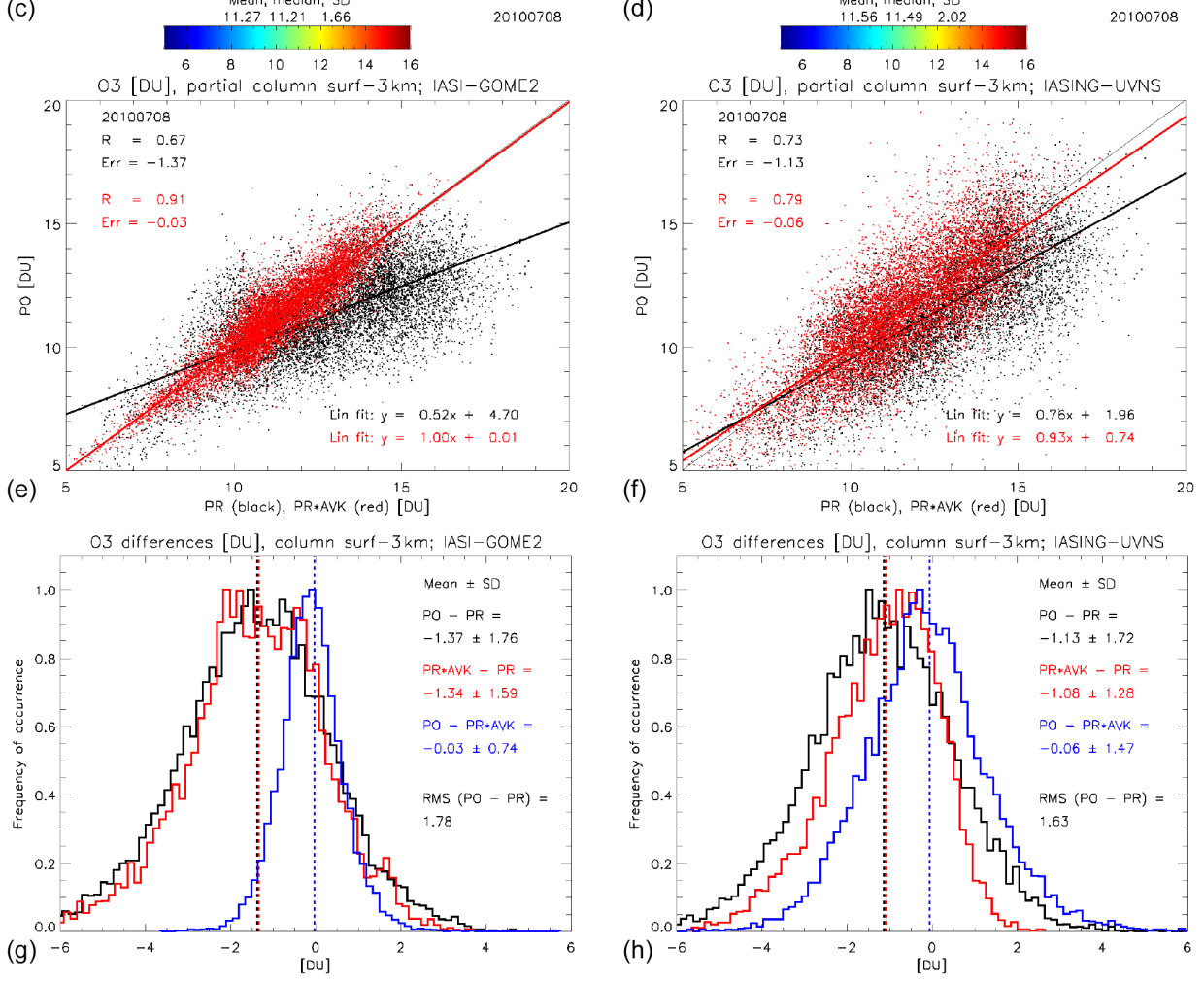

Figure 5. IASI+GOME-2 (a, c, e, g) and IASI-NG+UVNS (b, d, f, h) data, for 8 July 2010. (a, b) Maps of O3-3km [DU] from pseudoobservations (POs), grey colour indicates where CLF is larger than 0.3. Black lines indicate the [38, 39 $\left.{ }^{\circ} \mathrm{N}\right]$ latitude band. (c, d) Maps of O3-3km [DU] from AVK-smoothed pseudo-reality (PR $\times$ AVK). (e, f) Scatter plot of O3-3km [DU] from pseudo-observations ( $y$ axis) versus pseudo-reality (black, $x$ axis) and AVK-smoothed pseudo-reality (red, $y$ axis). Linear correlation coefficient, mean error and linear fit equation are reported in the figure. (g, h) Histograms of normalized frequency distribution of O3-3km differences [DU] between POs and PR (black), PR $\times$ AVK and PR (red), PO and PR $\times$ AVK (blue). Mean value and standard deviation of each difference is reported in the figure, together with PO-PR root mean square (rms). 

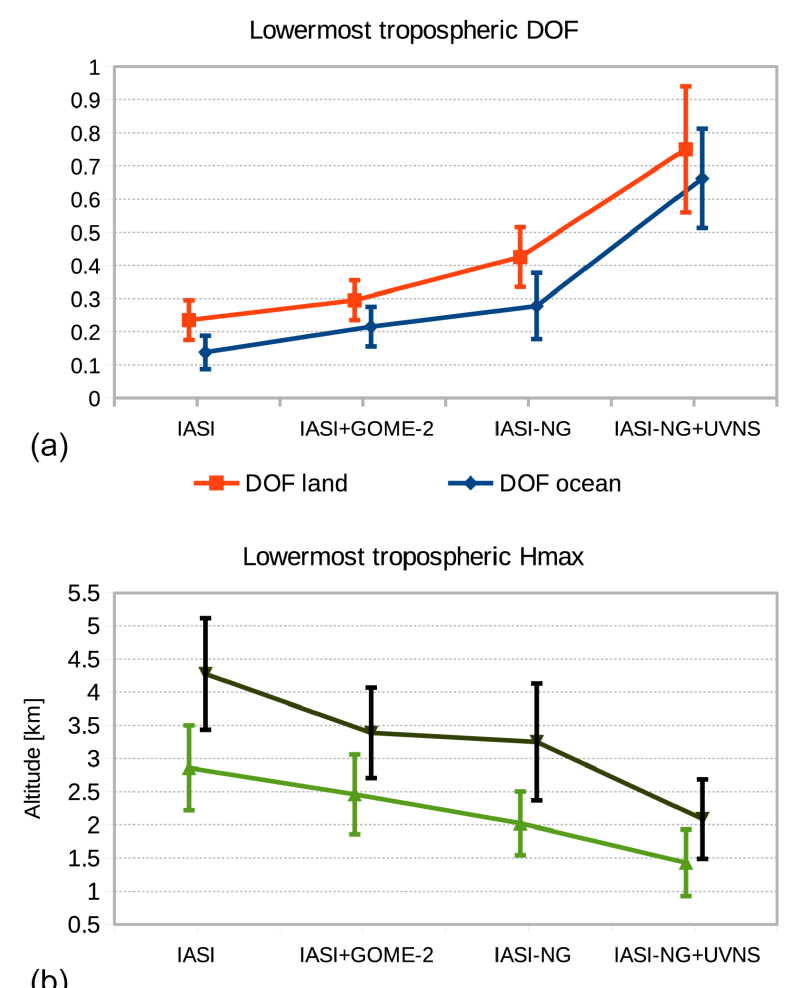

(b)
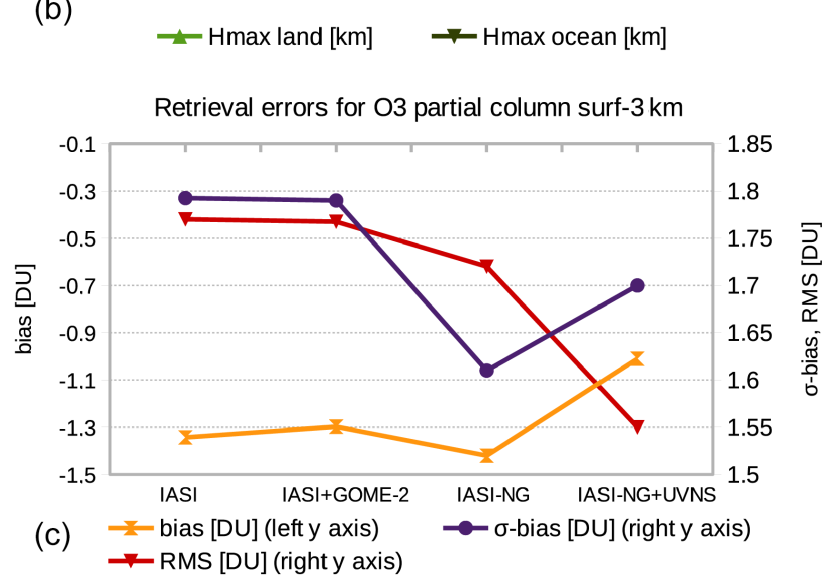

Figure 6. Average values of DOF-3km (a); Hmax-3km [km] (b); bias [DU], $\sigma$-bias [DU] and rms [DU] (c) of the O3-3km POPR distribution from IASI, IASI+GOME-2, IASI-NG and IASING+UVNS, for 8-11 July 2010 over Europe.

cal analysis of MOCAGE pseudo-reality with respect to real IASI+GOME-2 measurements and quantify retrieval errors and sensitivity for IASI+GOME-2 and IASI-NG+UVNS. Finally, we compare pseudo-observations of surface- $3 \mathrm{~km}$ ozone partial columns of the two observing systems.

\section{Nature run and pseudo-observation simulator}

The pseudo-reality is defined by the MOCAGE model (run at CERFACS laboratory), which provides vertical profiles of atmospheric state and composition variables on an hourly ba- sis. It uses 47 sigma-pressure hybrid levels up to $5 \mathrm{hPa}$ (approximately $35 \mathrm{~km}$ altitude) with a vertical resolution that increases from $150 \mathrm{~m}$ (lower troposphere) to approximately $1 \mathrm{~km}$ (stratosphere) and a horizontal resolution of $0.2 \times 0.2^{\circ}$. The same model configuration that provides operational air quality forecasts over Europe (Marécal et al., 2015) has been used for this study. We simulate LMT ozone pollution events over Europe, from 8 to 11 July 2010. Real ozone data, from surface network stations (AIRBASE), the Laboratoire d'Aérologie (LA) IASI product (Barret et al., 2011; Dufour et al., 2005) and MLS (Microwave Limb Sounder) V4.2 retrievals have been assimilated into the MOCAGE simulation to improve the accuracy of the modelled ozone fields at the surface, in the free troposphere and in the stratosphere. The assimilation is performed hourly using a 3D-Var algorithm, described in Jamouillé et al. (2012).

To simulate the multispectral retrievals from IASI+GOME-2, we select the two model grid points that are closest to IASI and GOME-2 ground pixels. For each point, KOPRA (for TIR) and VLIDORT (for UV) radiative transfer codes calculate the spectra, as observed by the satellite sensors and issued from radiation emitted, scattered (only UV) and absorbed by the surface and the atmosphere between 0 and $60 \mathrm{~km}$ altitude. All the profiles are sampled to $1 \mathrm{~km}$ layers in the radiative transfer calculations. As the MOCAGE model top is set at $35 \mathrm{~km}$ altitude, we complete the atmospheric vertical information between 30 and $50 \mathrm{~km}$ with data from a global MOCAGE simulation, run at coarser resolution with model top at $0.1 \mathrm{hPa}$ (Emili et al., 2014) and with climatological profiles above $50 \mathrm{~km}$.

Radiometric random noise for IASI and GOME-2 is added to the raw spectra before their ingestion into the retrieval algorithm. For TIR, the nominal noise standard deviation is taken from the literature as $20 \mathrm{nW} /\left(\mathrm{cm}^{2} \mathrm{~cm}^{-1} \mathrm{sr}\right.$ ) (Eremenko et al., 2008). Therefore, we added a noise value of $13 \mathrm{nW} /\left(\mathrm{cm}^{2} \mathrm{~cm}^{-1} \mathrm{sr}\right)$, roughly accounting for the reduction of noise due to apodization. For UV, noise is estimated for each wavelength using Muller matrix radiance response elements (Nowlan et al., 2011; Cai et al., 2012). The signal-to-noise ratio for GOME-2 is equal to 32 for wavelengths between 290 and $306 \mathrm{~nm}$ and equal to 350 between 325 and $340 \mathrm{~nm}$. Spectra are then ingested into the IASI+GOME-2 retrieval algorithm, which assumes no error in co-localization of TIR and UV measurements: each IASI spectrum (12 km-diameter pixel) is matched with the co-located GOME- 2 spectrum $\left(80 \times 40 \mathrm{~km}^{2}\right)$ within a distance of $1^{\circ}$ and without any averaging. IASI+GOME- 2 retrievals are calculated at the IASI ground resolution and processed independently for each IASI pixel.

Partial cloud cover and aerosols are not explicitly modelled in KOPRA, but their effects in the IASI spectra are partially compensated by offsets for each TIR micro-window (Eremenko et al., 2008; Dufour et al., 2010). In the UV spectra calculations, pixels with partial cloud cover are treated as a mixture of clear sky and cloudy scenes according to the 


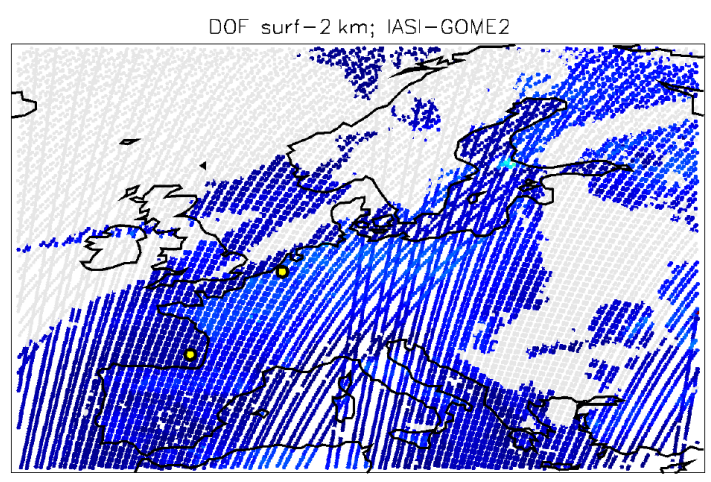

(a)
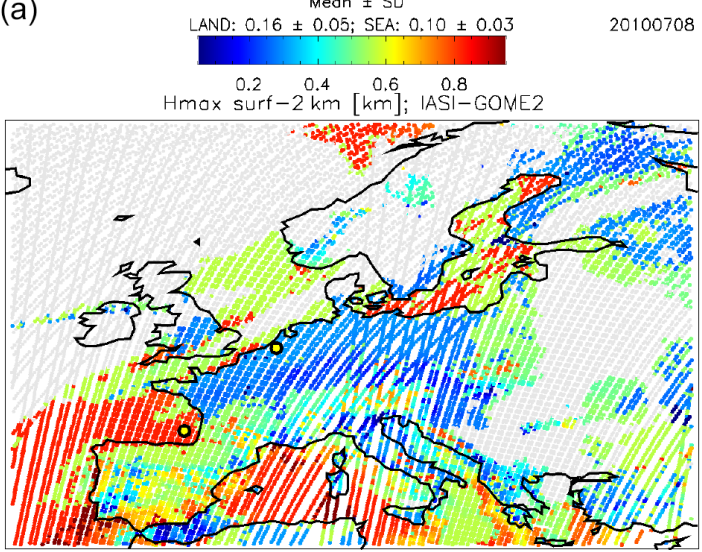

(c)

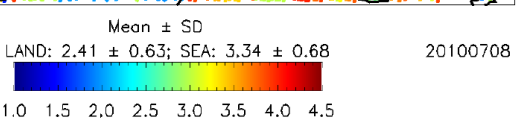

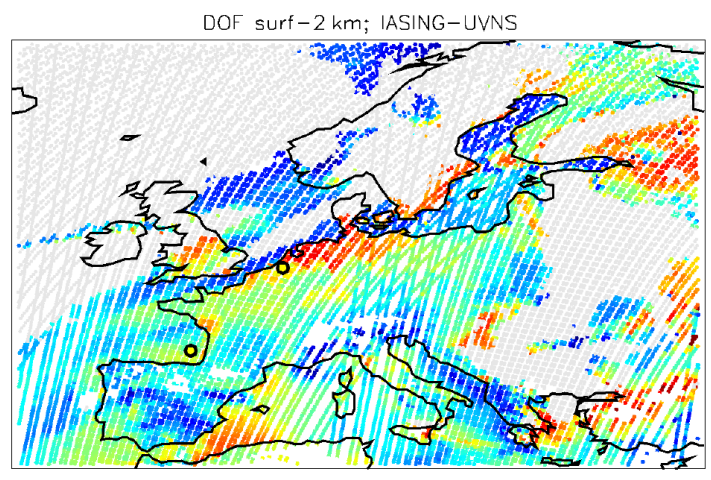

(b)

Mean $\pm S D$
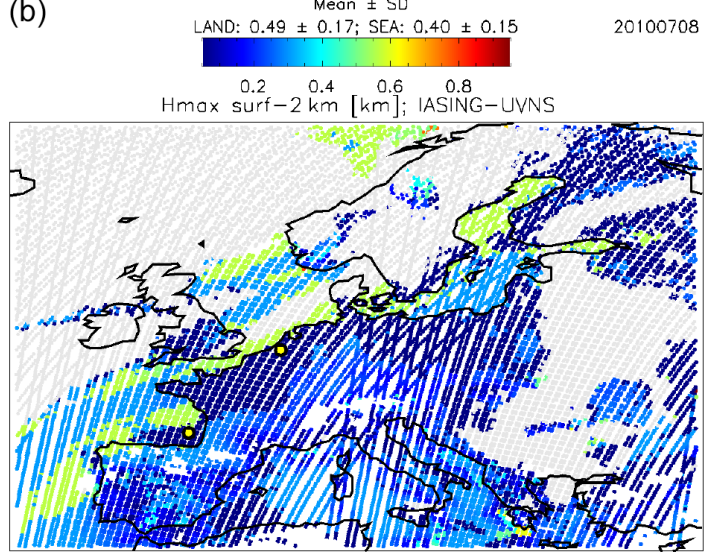

(d)

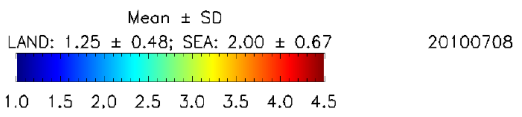

Figure 7. Maps of DOF-2km (a, b) and Hmax-2km [DU] (c, d) from IASI+GOME-2 (a, c) and IASI-NG+UVNS (b, d) pseudoobservations, for 8 July 2010.

independent pixel approximation (e.g. Cai et al., 2012). For more details on IASI+GOME-2 multispectral method refer to Cuesta et al. (2013).

The IASI-NG+UVNS retrieval method uses the same procedure as IASI+GOME-2, accounting for some differences in the specifications of the new instruments with respect to the existing ones that are summarized in Table 1 (for more information, visit https://directory.eoportal.org/web/eoportal/ satellite-missions). Note that for UVNS, only the UV-2 spectral channel is considered as the pixel resolution of the UV-1 is much coarser.

UVNS will have a higher SNR than GOME-2 but only half of its spectral resolution. IASI-NG noise and spectral resolution will be approximately half and a factor 2 finer than those of IASI, respectively. While IASI-NG will have the same spatial resolution as IASI and hence the same footprint (as MetOp and EPS-SG will fly on a similar polar orbit), UVNS will have a spatial resolution of $7.5 \mathrm{~km}$, which is much higher than that of GOME-2. A finer resolution will increase the number of pixels with ozone retrievals, decreasing the number of cloudy pixels with CLF $>0.3$. A finer (coarser) spectral resolution will increase (decrease) the retrieval ver- tical sensitivity to ozone. A higher SNR would improve the quality of the retrieval, leading to a higher vertical sensitivity and a smaller error. To better exploit IASI-NG+UVNS, we have designed a constraint matrix accounting for the capability of the new sensors. As done by Cuesta et al. (2013), we have adjusted the constraints to keep a similar retrieval error to IASI+GOME- 2 and enhance the sensitivity between the surface and $3 \mathrm{~km}$ altitude.

To simulate real IASI-NG+UVNS retrievals, we use the closest UVNS measurement with respect to the IASI-NG pixel centre.

\section{Inversion algorithm and ozone retrieval}

As previously mentioned, the inversion algorithm of IASI+GOME-2 is an altitude-dependent Tikhonov-Phillips regularization method for satellite nadir measurements (Cuesta et al., 2013). It is integrated into the KOPRAfit module and optimized for the lowermost tropospheric ozone observations. The constraint matrix and parameters are optimized to maximize the degree of freedom and minimize the error in the LMT, retaining a sufficient accuracy in the up- 
Table 1. Differences in nominal specifications of IASI-NG and UVNS (EPS-SG) with respect to IASI and GOME-2 (MetOp-B). For UVNS, only the UV-2 spectral channel is considered.

\begin{tabular}{|c|c|c|c|c|}
\hline & IASI (MetOp-B) & IASI-NG (EPS-SG) & GOME-2 (MetOp-B) & $\begin{array}{r}\text { UVNS (EPS-SG) } \\
\text { UV-2 channel }\end{array}$ \\
\hline Radiometric noise & $20 \mathrm{nW} /\left(\mathrm{cm}^{2} \mathrm{~cm}^{-1} \mathrm{sr}\right)$ & $10 \mathrm{nW} /\left(\mathrm{cm}^{2} \mathrm{~cm}^{-1} \mathrm{sr}\right)$ & - & - \\
\hline Spectral resolution & $0.50 \mathrm{~cm}^{-1}$ & $0.25 \mathrm{~cm}^{-1}$ & $\begin{array}{r}0.22-0.28 \mathrm{~nm} \\
(\lambda=290-306 \mathrm{~nm}) \\
0.24-0.30 \mathrm{~nm} \\
(\lambda=325-340 \mathrm{~nm})\end{array}$ & $\begin{array}{r}0.5 \mathrm{~nm} \\
(\lambda=300-370 \mathrm{~nm})\end{array}$ \\
\hline Spectral sampling & $0.25 \mathrm{~cm}^{-1}$ & $0.125 \mathrm{~cm}^{-1}$ & $0.12 \mathrm{~nm}$ & $0.15 \mathrm{~nm}$ \\
\hline SNR & - & - & $\begin{array}{r}32 \\
(\lambda=290-306 \mathrm{~nm}) \\
350 \\
(\lambda=325-340 \mathrm{~nm})\end{array}$ & $\begin{array}{r}1000 \\
(\lambda=300-370 \mathrm{~nm})\end{array}$ \\
\hline Spatial resolution & $\begin{array}{l}12 \mathrm{~km} \text {-diameter pixel spaced } \\
\text { by } 25 \mathrm{~km} \text { at nadir }\end{array}$ & $\begin{array}{l}12 \mathrm{~km} \text {-diameter pixel spaced } \\
\text { by } 25 \mathrm{~km} \text { at nadir }\end{array}$ & $80 \times 40 \mathrm{~km}^{2}$ & $7.5 \times 7.5 \mathrm{~km}^{2}$ \\
\hline
\end{tabular}

per troposphere and in the stratosphere (Cuesta et al., 2013). Three different ozone a priori profiles, derived from climatological values of McPeter et al. (2007), are selected depending on the pseudo-real tropopause height (TH). We use a midlatitude a priori $\left(30-60^{\circ} \mathrm{N}\right)$ for $\mathrm{TH}$ between 10 and $14 \mathrm{~km}$, a tropical a priori $\left(20-30^{\circ} \mathrm{N}\right)$ for higher $\mathrm{TH}$ and a polar $(60$ $90^{\circ} \mathrm{N}$ ) for $\mathrm{TH}$ lower than $10 \mathrm{~km}$. The ozone profile (volume mixing ratio) is obtained by inverting the measurement vector (built up by merging together IASI TIR atmospheric radiances with GOME-2 UV earth reflectances) and jointly adjusting the water vapour profiles, offsets for each TIR microwindow, wavelength shifts for the UV radiance and irradiance spectra, multiplicative factors of the ring spectrum, surface albedo multiplicative factors and a factor for cloud fraction used in the UV forward calculations.

Here, we provide a quantitative tool to analyse and quantify the error budget associated with each algorithm. If the inversion occurs in an incrementally linear regime, we can consider that the total error of a constrained least square fit method is separated into three components (Rodgers, 2000): (1) a measurement error, which is random and due to instrumental limitations; (2) a smoothing error, which is due to the specific retrieval techniques and to the limited sensitivity of the radiance measurements to the vertical distribution of the considered gas; and (3) a systematic error.

The KOPRAfit module provides the AVK matrix of the inversion, describing the vertical sensitivity of retrievals to the true profiles. For a given column, each row shows the fractional height-resolved part of information for the retrieval that comes from the observed spectrum, while the remaining fraction comes from the a priori. The peak value of each AVK column indicates the height of maximum sensitivity to true profiles for the selected altitude. If we integrate the AVK over the rows (i.e. over the different altitudes), we can deduce the height of maximum sensitivity (Hmax) of the retrieval. In the following, we will be interested in the altitude of maximum sensitivity of LMT ozone retrievals between the surface and $3 \mathrm{~km}$ altitude (Hmax-3km). According to Rodgers (2000), the trace of AVK matrix gives the DOF a scalar quantity, indicating the number of independent pieces of information within a measurement. For the LMT, the DOF of ozone partial columns is obtained from the trace of AVK up to $3 \mathrm{~km}$ $(\mathrm{DOF}-3 \mathrm{~km})$. It is an easy and direct parameter to quantify the vertical sensitivity of each retrieval.

From 2017, IASI+GOME-2 ozone retrievals are available at the AERIS data centre (http://www.aeris-data.fr). An example of real IASI+GOME-2 products is provided in Fig. 1, which shows $\mathrm{O}_{3}$ partial columns (top image) integrated between the surface and $3 \mathrm{~km}$ a.s.l. (O3-3km) as well as DOF$3 \mathrm{~km}$ (middle) and Hmax-3km (bottom) for 8 July 2010. White gaps indicate a lack of values due to the presence of relatively high cloud cover $(>30 \%)$, unavailability of satellite data or invalid retrievals. The DOF- $3 \mathrm{~km}$ map indicates that $03-3 \mathrm{~km}$ estimates are closer to true profiles over land, where DOF-3km is higher $(0.28)$ than over ocean $(0.22)$ because of a stronger thermal contrast (i.e. the temperature difference between the surface and the lowest atmospheric layer). DOF and Hmax are the two diagnostic parameters that will be used in this work to quantify the sensitivity of a retrieval method.

The convolution of the pseudo-reality with the AVK matrix (generally referred to as AVK smoothing) gives an estimate of what retrievals would be without accounting for instrumental limitations (radiometric noise). The smoothing error is directly linked to the difference between AVKsmoothed pseudo-reality and pseudo-reality. It can be estimated from the standard deviation of the frequency distribution of this difference. The measurement error (i.e. due to 
03 [DU], PO, partial column surf-2 km; IASI-GOME2
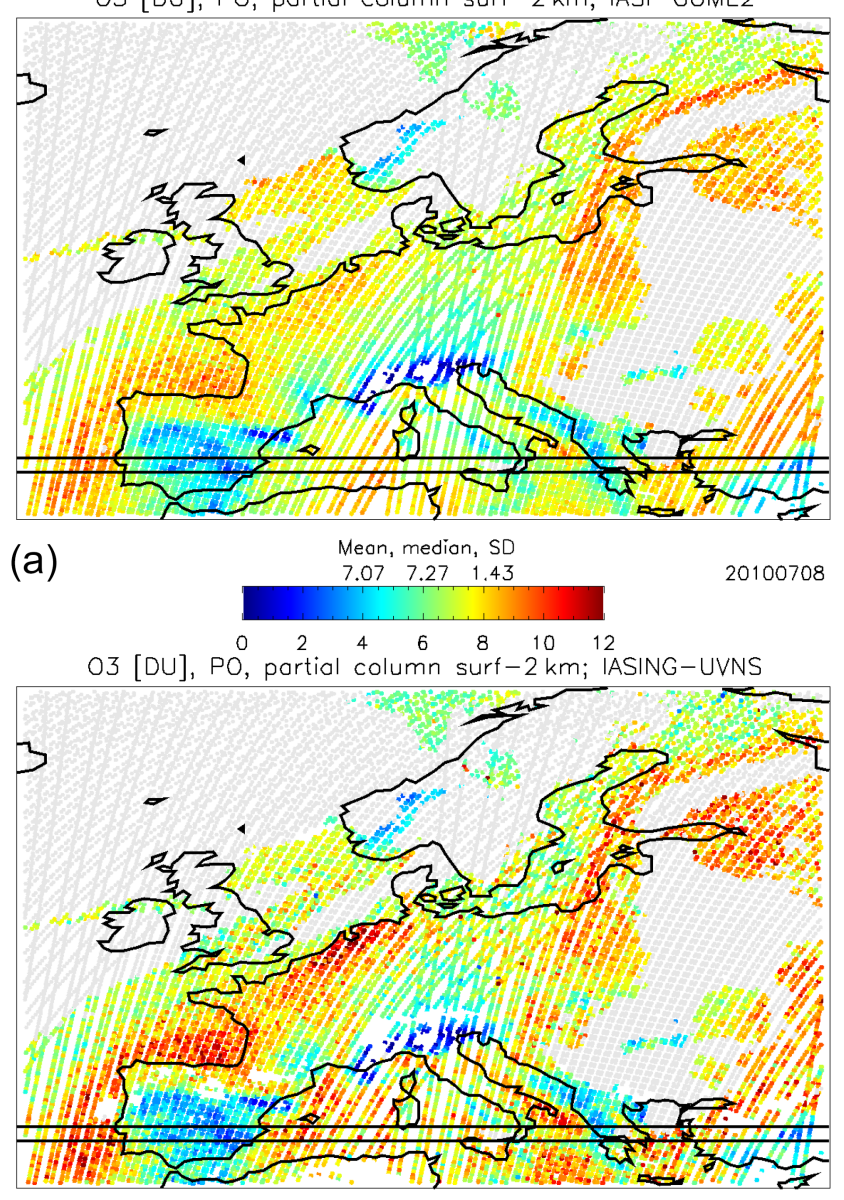

(b)
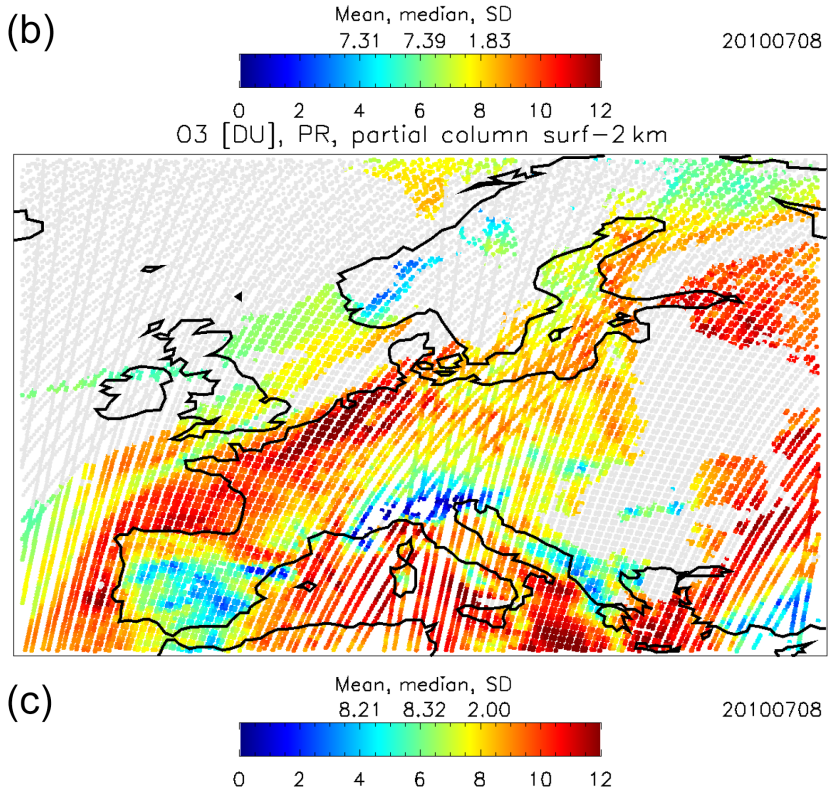

Figure 8. Maps of O3-3km [DU] from IASI+GOME-2 (a) and IASI-NG+UVNS (b) pseudo-observations and PR (c) for 8 July 2010. radiometric noise) can be estimated from the standard deviation of the difference between pseudo-observations and AVK-smoothed pseudo-reality.

Finally, the difference between pseudo-observations and pseudo-reality (bias) gives an estimate of the inversion algorithm accuracy. Its standard deviation ( $\sigma$-bias) quantifies the total error which is an estimate of the algorithm precision.

\section{MOCAGE pseudo-reality}

In a first analysis, we observed that MOCAGE strongly underestimates the cloud fraction (CLF), which never exceeds a value of 0.3 . Therefore, we have estimated an empirical conversion from MOCAGE cloud fraction to more realistic values used as inputs of the pseudo-reality. We then compared the MOCAGE cloud fraction with GOME-2 a priori values, given from an external algorithm called FRESCO (Koelemeijer et al., 2001), for the whole 8-10 July time period. As IASI+GOME-2 retrieval sensitivity to LMT ozone is significantly reduced when CLF $>0.3$, such cloudy pixels are excluded. For those pixels with $\mathrm{CLF}<0.3$, we defined two correction factors that minimize the differences in CLF frequency distribution and mean CLF, between the two data sets. The corrected cloud fraction is calculated as CLF $=20.70 \times\left(\right.$ CLF_mocage $\left.{ }^{1.2}\right)$, where CLF_mocage represents the original CLF given by MOCAGE. We assume the presence of only low clouds with cloud top pressures above $700 \mathrm{hPa}$.

As previously mentioned, a more realistic representation of ozone horizontal variability is obtained by assimilation of real ozone data into MOCAGE. To test the reliability of pseudo-real ozone concentration, we compared O3$3 \mathrm{~km}$ from MOCAGE with real IASI+GOME-2 retrievals. Figure 2 (left) shows the map of model O3-3km data for 8 July 2010. Light grey indicates where cloud fraction is larger than 0.3 . For consistency with Fig. 1, we only show those MOCAGE pixels that would have been selected by IASI+GOME-2 algorithm on that day (i.e. co-located and near-simultaneousness with IASI and GOME-2 footprint at the time of MetOp overpass).

The normalized frequency distributions of Fig. 2 (right) show an overall consistency between MOCAGE outputs and IASI+GOME-2 retrievals in terms of O3-3km magnitude and spatial distribution. MOCAGE (red) seems to overestimate the regional mean O3-3km (black) by $2.16 \mathrm{DU}$ ( $21 \%)$. This difference is mostly due to the reduced sensitivity of IASI+GOME- 2 retrievals to ozone below $3 \mathrm{~km}$ altitude. If we account for this effect, smoothing the PR by real AVK (PR $\times$ realAVK, blue), the resulting O3-3km distribution shows an average value much closer to real data. A positive bias of MOCAGE at the LMT is also shown by Zyryanov et al. (2012). The standard deviation of IASI+GOME-2 that is larger than MOCAGE outputs might be due to the radio- 
metric noise of real satellite measurements and to the naturally higher variability of real data than of model simulations.

The analysis of pseudo-reality was also performed by comparison of surface temperatures $\left(T_{\mathrm{S}}\right)$ from MOCAGE and retrievals, using IASI real spectra within the IASI+GOME-2 algorithm. Figure 3 shows maps of $T_{\mathrm{S}}$ derived from real IASI measurements (top left) and model simulations (top right) for 8 July 2010, together with the histogram of their normalized frequency distribution over land (bottom left) and over ocean (bottom right). We consider only those pixels with skin temperature in the $5-45^{\circ} \mathrm{C}$ range, where the absolute $T_{\mathrm{s}}$ difference between real measurements and MOCAGE is lower than $10^{\circ} \mathrm{C}$. Histograms of Fig. 3 clearly indicate that MOCAGE (red) overestimates, on average, the ocean surface temperature and underestimates land surface temperature with respect to IASI data (black). This is true for the entire 8-10 July time period, and the mean difference between real and MOCAGE $T_{\mathrm{s}}$ is equal to -1.42 (ocean) and $+0.67^{\circ} \mathrm{C}$ (land). Further analysis also shows that MOCAGE overestimates the atmospheric temperature profile in the first $6 \mathrm{~km}$ altitude. For the whole period, the mean difference between real and MOCAGE temperature is equal to - 2.69 (0$1 \mathrm{~km}),-1.41(1-2 \mathrm{~km}),-1.51(2-3 \mathrm{~km}),-1.14(3-4 \mathrm{~km})$, $-0.88(4-5 \mathrm{~km})$ and $-0.51(5-6 \mathrm{~km}){ }^{\circ} \mathrm{C}$. These values have been used to modify MOCAGE temperatures before running radiative calculations and inversion algorithms in order to consider realistic thermal contrasts for pseudo-reality. It should be mentioned that this work of nature run calibration against real observations and especially for meteorological variables (important for the retrievals) is mandatory to get a realistic pseudo-reality. We believe that it is one important strength of this work to have taken care of these aspects that are often not really tackled in OSSE studies.

\section{Results}

After the correction of MOCAGE cloud fraction and temperature fields toward more realistic values, we have used MOCAGE atmospheric profiles to simulate TIR radiances and UV reflectances by KOPRA and VLIDORT respectively. We then added radiometric random noise to raw spectra and processed the simulated spectra by IASI+GOME-2 and IASI-NG+UVNS inversion algorithms. Retrievals are provided at the IASI ground resolution. Statistics of retrieval sensitivity and LMT ozone partial columns are presented in the following paragraph.

\subsection{Retrieval sensitivity}

As previously mentioned, multispectral retrieval sensitivity is quantified in terms of lowermost tropospheric DOF and Hmax. The first row of Fig. 4 shows DOF-3km maps from IASI+GOME-2 (left) and IASI-NG+UVNS (right). To test the general consistency of retrieval performances

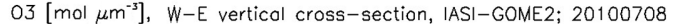

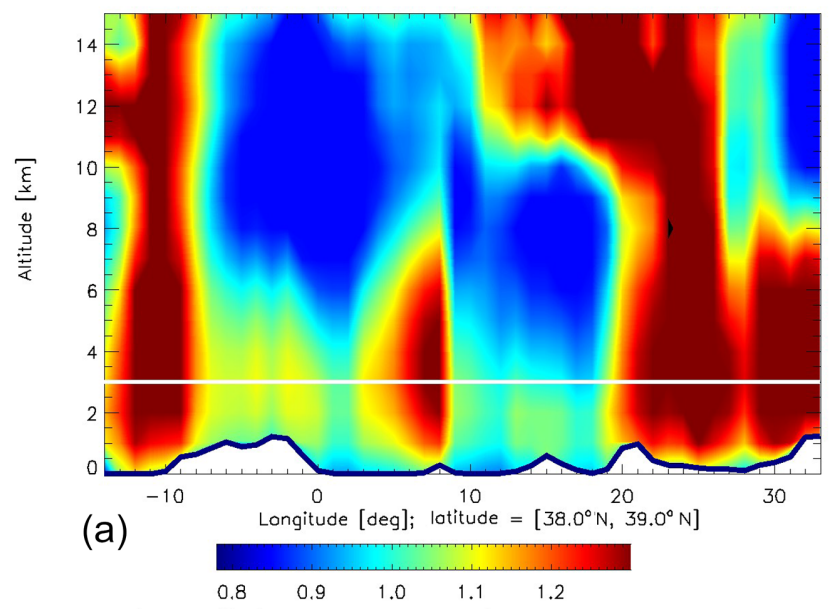

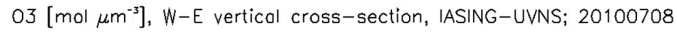

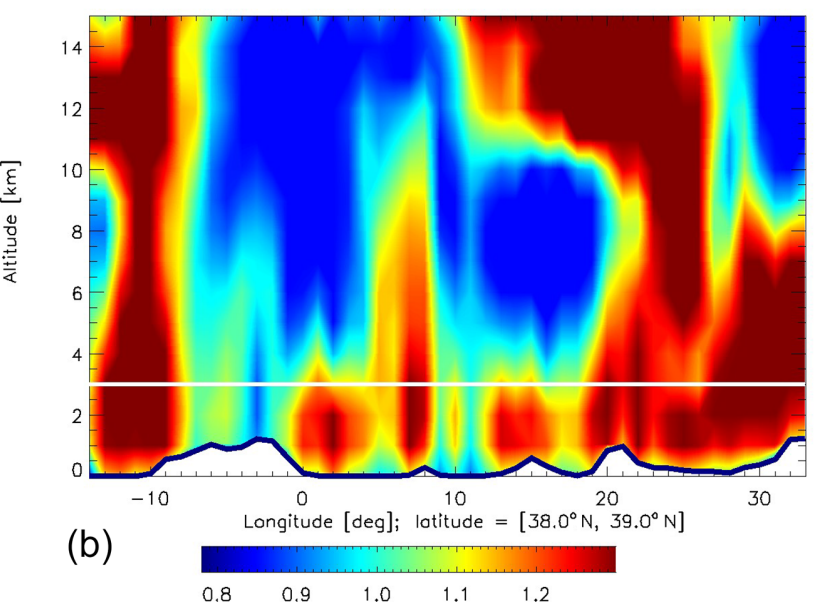

$03\left[\mathrm{~mol} \mu \mathrm{m}^{-3}\right], \mathrm{W}-\mathrm{E}$ vertical cross-section, PR; 20100708

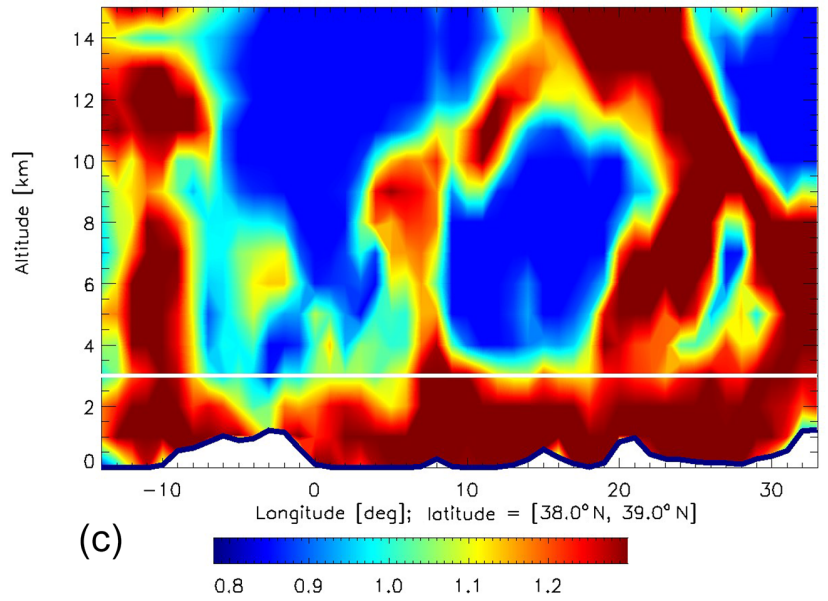

Figure 9. Cross section of ozone concentration [molecules $\mu \mathrm{m}^{-3}$ ] in the latitude band $\left[38,39^{\circ} \mathrm{N}\right]$ (as shown in Fig. 5, first row), from the surface to $15 \mathrm{~km}$ altitude, for 8 July 2010. Data are averaged horizontally with a resolution of $1 \times 1^{\circ}$. (a) IASI+GOME-2 retrievals. (b) IASI-NG+UVNS retrievals. (c) MOCAGE pseudoreality. White line indicates an altitude of $3 \mathrm{~km}$. 
$\mathrm{O} 3\left[\mathrm{~mol} \mu \mathrm{m}^{-3}\right]$, W-E vertical cross-section, IASI-GOME2; 20100711
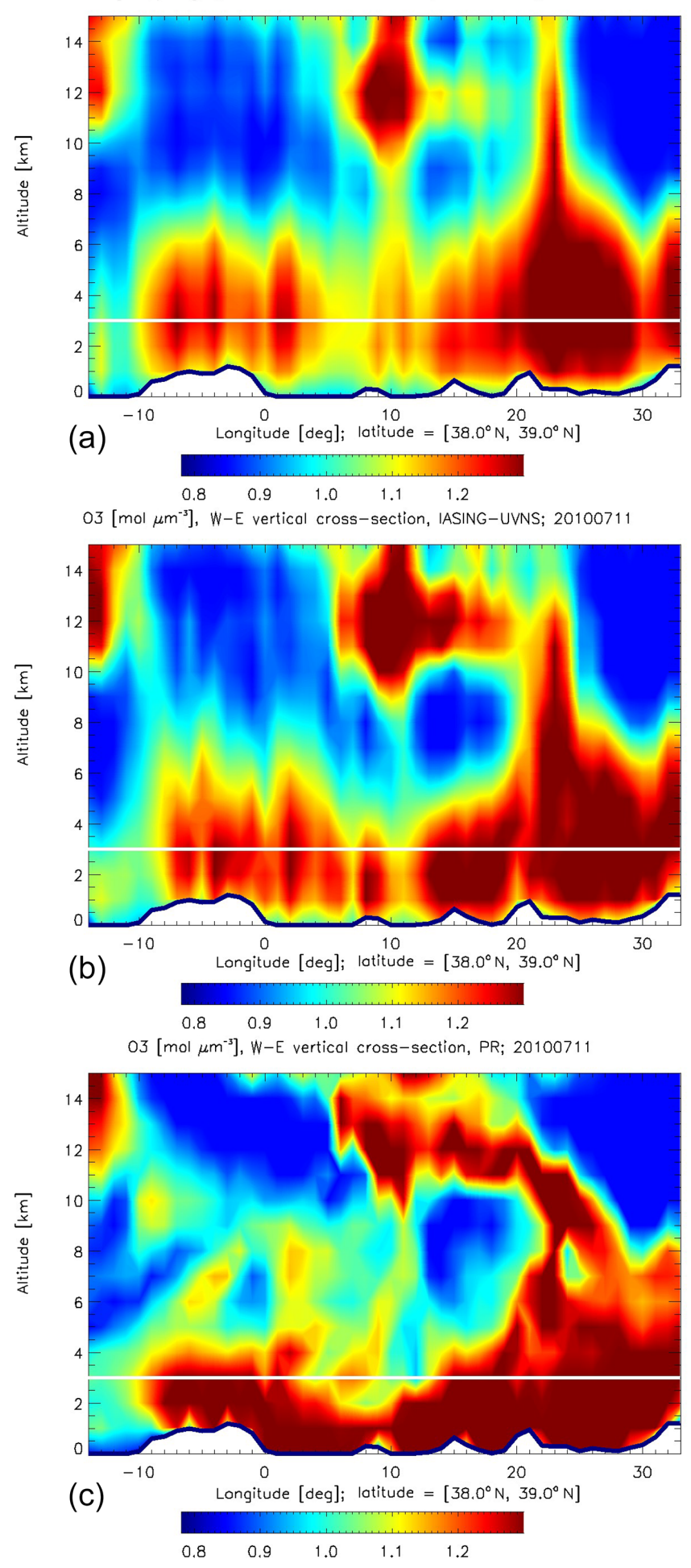

Figure 10. Same as Fig. 9, but for 11 July 2010.

between the POS and reality, pseudo-real DOF- $3 \mathrm{~km}$ and Hmax-3km from IASI+GOME-2 (Fig. 4) are compared with real satellite products (Fig. 1). We already observed that the MOCAGE geographical distribution of $\mathrm{O} 3-3 \mathrm{~km}$ is realistic over Europe (Figs. 1 and 2). Figure 4 also shows that pseudo-real and real retrievals from IASI+GOME-2 are consistent in terms of DOF-3km (first row) and Hmax$3 \mathrm{~km}$ (second row) for both magnitude and spatial variability. On average, the regional DOF- $3 \mathrm{~km}$ is equal to $0.29 \pm 0.07$ (over land) and $0.21 \pm 0.05$ (over ocean) for the synthetic retrievals and to $0.29 \pm 0.08$ (over land) and $0.21 \pm 0.08$ (over ocean) for the real case. The peak of maximum sensitivity in the LMT is equal to $2.49 \pm 0.62 \mathrm{~km}$ (over land) and $3.40 \pm 0.68$ (over ocean) for the synthetic retrievals and to $2.44 \pm 0.97$ (over land) and $3.23 \pm 1.10 \mathrm{~km}$ (over ocean) for the real case. Results are consistent (within statistical uncertainties) with real IASI+GOME-2 sensitivity values obtained by Cuesta et al. (2013) over the same region for the 1920 August 2009. They find a DOF- $3 \mathrm{~km}$ of $0.34 \pm 0.04$ (land) and $0.23 \pm 0.04$ (ocean), and a Hmax-3km of $2.20 \pm 0.50$ (land) and $3.42 \pm 0.59$ (ocean).

The IASI-NG+UVNS map of DOF-3km (right) shows an average increase in the degree of freedom at $3 \mathrm{~km}$ over land $(150 \%)$ and ocean $(200 \%)$ with respect to IASI+GOME2 , with mean values that grow from 0.29 (land) and 0.21 (ocean) with IASI+GOME-2 to 0.72 (land) and 0.64 (ocean) with IASI-NG+UVNS. Note that IASI-NG+UVNS uses an optimized constraint to enhance sensitivity in the LMT. Accordingly, with the new spectral method the peak of LMT sensitivity to ozone (Hmax-3km, second row of Fig. 4) decreases on average by about $1.1 \mathrm{~km}$ over land (from 2.50 to $1.41 \mathrm{~km}$ ) and $1.27 \mathrm{~km}$ over ocean (from 3.40 to $2.13 \mathrm{~km}$ ). Sensitivity differences between land and ocean are strong for IASI+GOME- 2 and are also present in IASI-NG+UVNS retrievals because of the different thermal contrasts which are greater over land. The third row of Fig. 4 shows that normalized frequency distributions of DOF-3km are wider and shifted to higher values when using new-generation sensors (right image) for both land (red) and ocean (blue). It is remarkable that in several cases the IASI-NG+UVNS method shows a DOF- $3 \mathrm{~km} \geqslant 0.8$ (22\% of total) and a Hmax- $3 \mathrm{~km}$ $\leqslant 1.5 \mathrm{~km}(37 \%$ of total $)$.

The fourth and fifth rows of Fig. 4 report two examples of AVK vertical profiles at retrieval altitudes of 0,1 , $2,3 \mathrm{~km}$ (red) and 4, 5, $6 \mathrm{~km}$ (blue) and 7, 8, 9, 10, 11, $12 \mathrm{~km}$ (black) for two specific pixels over land and ocean (black-yellow spot in maps) with thermal contrast (reported in the figure) particularly high and equal to 14.5 (land) and $5.9^{\circ} \mathrm{C}$ (ocean). Stratospheric DOF (surface-60 km) is consistently increased with IASI-NG+UVNS, by $1.59(+31 \%)$ over land and $1.40(+29 \%)$ over ocean, and tropospheric DOF (surface- $12 \mathrm{~km}$ ) is increased by $1.19(+75 \%)$ over land and $1.09(+76 \%)$ over ocean. However, the maximum gain is obtained in the LMT where DOF-3km increases by 0.61 $(+179 \%)$ over land and $0.58(+305 \%)$ over ocean. The dotted line indicates the height of maximum sensitivity in the LMT. As expected, IASI+GOME-2 shows better retrieval performances over land $(H \max -3 \mathrm{~km}=2 \mathrm{~km})$ than over ocean 


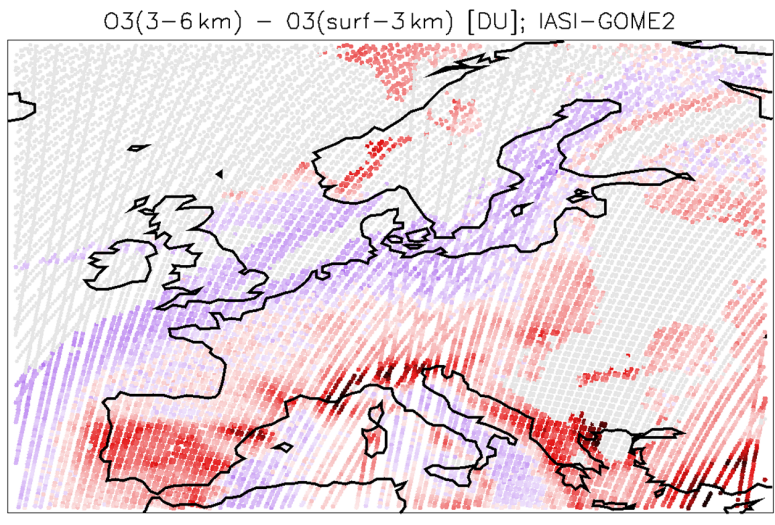

(a)
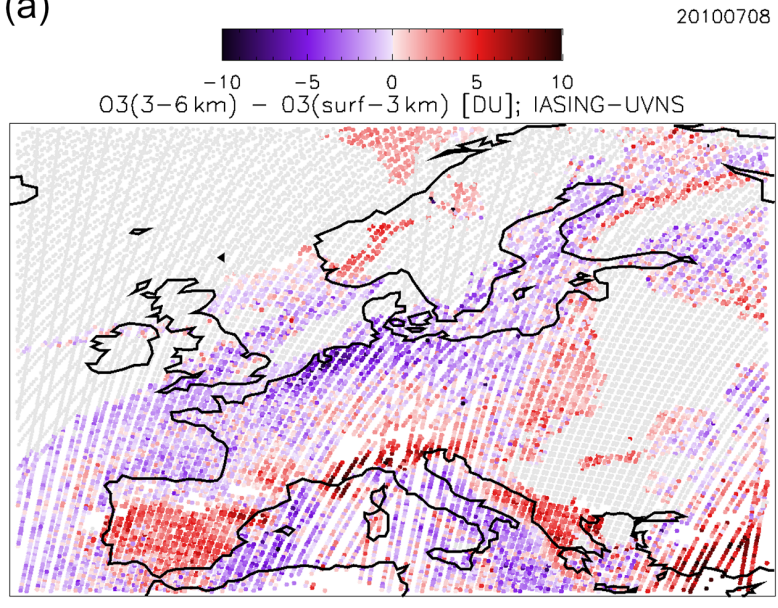

(b)
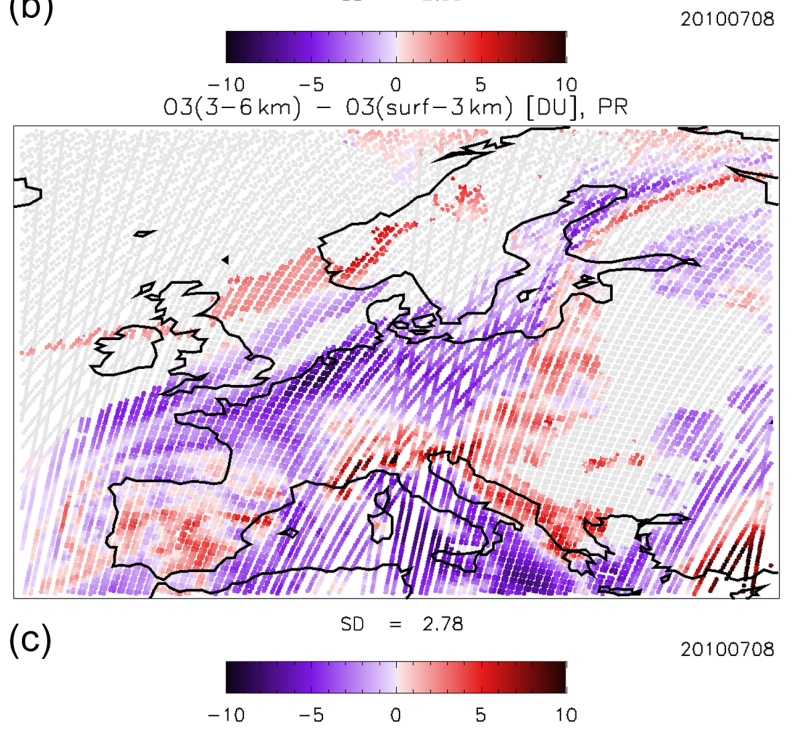

Figure 11. Maps of pixel-by-pixel difference between ozone partial columns [DU] calculated in the surface $-3 \mathrm{~km}$ and $3-6 \mathrm{~km}$ altitude bands, for 8 July 2010. Negative values (purple) indicate stronger ozone concentration in the LMT than above. Regional standard deviation $(\mathrm{SD})$ value is reported in the figure.
$($ Hmax $-3 \mathrm{~km}=4 \mathrm{~km})$. The use of IASI-NG+UVNS further decreases Hmax-3km over land and even more over ocean, down to $1 \mathrm{~km}$ altitude in both cases.

For the whole time period (8-11 July), averaged values of regional mean DOF- $3 \mathrm{~km}$ and Hmax-3km from IASI+GOME- 2 and IASI-NG+UVNS are presented in Table 2, with real IASI+GOME-2 data reported in parentheses below pseudo-real ones.

\subsection{LMT ozone retrievals}

Figure 5 shows maps of O3-3km pseudo-observations (first row) and AVK-smoothed pseudo-reality (second row), from IASI+GOME-2 (left) and IASI-NG+UVNS (right). In terms of absolute ozone concentrations, both IASI+GOME-2 and IASI-NG+UVNS have an overall good agreement with the MOCAGE pseudo-reality. The two multispectral methods differ by less than $3 \%$ in estimating the mean $03-3 \mathrm{~km}$ value over the whole region. However IASI-NG+UVNS shows a larger spatial variability and captures high $\mathrm{O} 3-3 \mathrm{~km}$ values off the coast of northern Spain, France, the Netherlands, and the Mediterranean basin more efficiently. This is even more visible looking at the AVK-smoothed pseudo-reality (Fig. 5, second row), where radiometric noise is not present. O3$3 \mathrm{~km}$ patterns smoothed by IASI-NG+UVNS averaging kernels are closer to MOCAGE product (Fig. 2) because of the stronger sensitivity to true profiles.

As a consequence, the correlation between pseudoretrievals and pseudo-reality is enhanced for IASING+UVNS. Figure 5 (third row) presents the scatter plot of O3-3km pseudo-observations versus pseudo-reality (black) and AVK-smoothed pseudo-reality (red). With respect to existing instruments (left image), the product of new-generation sensors (right image) are better correlated to MOCAGE data. The correlation coefficient between PO and PR (black) increases from 0.67 to 0.73 (+9\%) and the linear fit slope (reported in the figure) of the dispersion plot increases from 0.52 to $0.76(+46 \%)$, a sign that high O3$3 \mathrm{~km}$ values (larger than $\sim 8.5 \mathrm{DU}$ ) are less underestimated. On the other hand, the correlation coefficient between PO and PR $\times$ AVK (red) decreases from 0.91 to $0.79(-13 \%)$, as well as the linear fit slope (from 1 to $0.85,-15 \%$ ), a sign of a larger measurement error for IASI-NG+UVNS than for IASI+GOME-2 (quantified afterwards).

The fourth row of Fig. 5 shows the normalized frequency distributions of (pixel-by-pixel) differences in $03-3 \mathrm{~km}$ between pseudo-observations and pseudo-reality (PO-PR, black), AVK-smoothed pseudo-reality and pseudo-reality (PR $\times$ AVK-PR, red), and pseudo-observation and AVKsmoothed pseudo-reality (PO-PR $\times$ AVK, blue). With respect to IASI+GOME-2, the IASI-NG+UVNS mean value of PO-PR distribution (retrieval mean bias) decreases from -1.37 to $-1.13(-17 \%)$. The total retrieval error, quantified by the standard deviation of the mean bias, does not vary significantly (from 1.76 to $1.72,-2 \%$ ) because of the net 

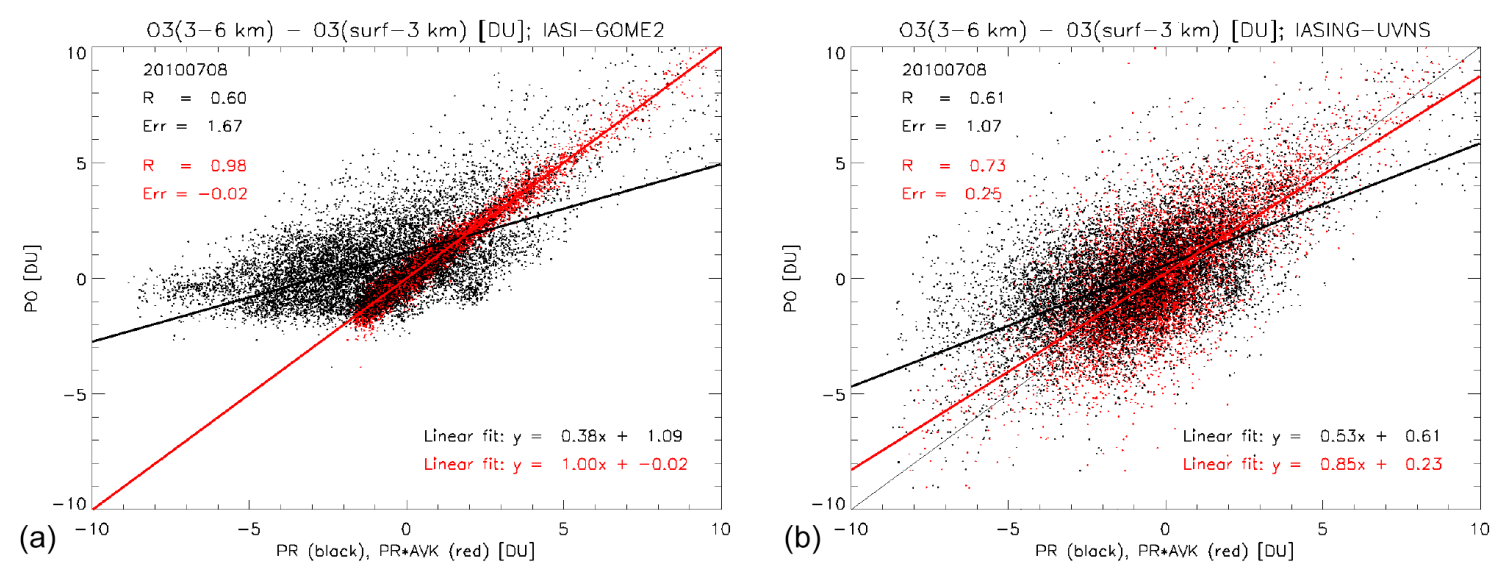

Figure 12. Same data as in Fig. 11. IASI+GOME-2 (a) and IASI-NG+UVNS (b) pseudo-observations (POs, $y$ axis) versus pseudo-reality (PR, black, $x$ axis) and AVK-smoothed pseudo-reality $(\mathrm{PR} \times \mathrm{AVK}$, red, $x$ axis). Linear correlation coefficient, mean error and linear fit equation are reported in the figure.

balance between the decreasing smoothing error (from 1.59 to $1.28,-19 \%$ ) and the increasing measurements error (from 0.74 to $1.47,+92 \%)$. At the same time, the root mean square (rms) decreases from 1.78 to $1.63(-8 \%)$. These results indicate an overall higher quality of the retrieval (smaller rms) when using the EPS-SG sensor instead of MetOp instrumentation, with a global gain in retrieval accuracy (smaller bias) and an almost constant retrieval precision (slightly smaller $\sigma$-bias).

For the whole time period ( $8-11$ July), Table 2 reports regional means of the linear correlation coefficient $R$, between pseudo-observations and pseudo-real data of O3-3km, as well as the bias, the $\sigma$-bias and the rms of the PO-PR distribution, for both IASI+GOME-2 and IASI-NG+UVNS.

Figure 6 graphically shows the mean values of DOF- $3 \mathrm{~km}$ (middle), Hmax-3km (middle), bias, $\sigma$-bias and rms (bottom) of the O3-3km PO-PR distribution from IASI+GOME2 and IASI-NG+UVNS (Table 2), together with these same values from IASI and IASI-NG alone, simulated over the same area and time period. Note that in the case of IASI alone, the POS seems to overestimate the retrieval performances with a Hmax $-3 \mathrm{~km}$ over land equal to $2.86 \pm 0.64 \mathrm{~km}$, which is only $400 \mathrm{~m}$ above that of IASI+GOME- 2 instead of the $800 \mathrm{~m}$ expected by Cuesta et al. (2013). For what concerns DOF- $3 \mathrm{~km}$ and Hmax- $3 \mathrm{~km}$, IASI+GOME-2 represents a clear improvement to IASI alone, while technical advances of IASI-NG allow retrieval performances that are even higher than those from IASI+GOME-2. When IASI-NG is coupled with UVNS, the IASI-NG+UVNS synergism overpasses the retrieval skills of all other configurations by far.

The rms of the PO-PR difference distribution, which is an estimate of the overall retrieval quality combining accuracy and precision, decreases monotonically from IASI to IASING+UVNS. For what concerns the bias and the $\sigma$-bias, the results are consistent with the design of the constraint matrix of IASI-NG+UVNS, which is less constrained than in
IASI, IASI+GOME-2 and IASI-NG algorithms in order to increase the vertical sensitivity to near-surface ozone. This particular choice leads to a higher accuracy and a smaller smoothing error (lower bias) for IASI-NG+UVNS than all other retrieval methods, but also to a larger measurement error that enhances the total retrieval error ( $\sigma$-bias) of IASING+UVNS with respect to IASI-NG.

The high-quality retrieval skills of IASI-NG+UVNS below $3 \mathrm{~km}$ altitude suggest going deeper into the lowermost troposphere and investigating ozone sensitivity in the surface- $2 \mathrm{~km}$ layer. Figure 7 shows the DOF- $2 \mathrm{~km}$ (top) and the Hmax-2km (bottom) for 8 July 2010, from IASI+GOME-2 (left) and IASI-NG+UVNS (right). With respect to LMT, the retrieval performances of IASI+GOME2 degrade sensibly in terms of DOF $(0.16 \pm 0.05$ over land $0.10 \pm 0.03$ over ocean) as Hmax- $2 \mathrm{~km}$ remains above $2 \mathrm{~km}$ latitude $(2.41 \pm 0.63 \mathrm{~km}$ over land and $3.34 \pm 0.68 \mathrm{~km}$ over ocean). On the contrary, IASI-NG+UVNS still shows a relatively high DOF- $2 \mathrm{~km}$ of $0.49 \pm 0.17$ (land) and $0.40 \pm 0.15$ (ocean) and a low Hmax- $2 \mathrm{~km}$ of $1.25 \pm 0.48$ (land) and $2.0 \pm 0.67 \mathrm{~km}$ (ocean), which are even better than IASI+GOME- 2 for the surface- $3 \mathrm{~km}$ partial column.

For the whole time period, the IASI-NG+UVNS regional mean DOF-2km is equal to $0.52 \pm 0.17$ (land) and $0.42 \pm 0.15$ (ocean) with a Hmax-2km of $1.29 \pm 0.49$ (land) and $1.96 \pm 0.63 \mathrm{~km}$ (ocean). As a consequence, the map of O3-2km pseudo-retrievals from IASI-NG+UVNS (Fig. 8) is much closer to reality than from IASI+GOME-2. In particular, high ozone values are less underestimated over the Netherlands and the Mediterranean basin (especially off the coast of eastern Spain and southern Italy), where low-level ozone layers are present. 
Table 2. Averaged values (8-11 July 2010) of regional mean degree of freedom in the LMT (DOF-3km), altitude of maximum sensitivity in the LMT (Hmax-3km [km]), linear correlation coefficient between PR and PO of O3-3km, together with the mean value (bias [DU]), the standard deviation ( $\sigma$-bias [DU]) and the root mean square (rms [DU]) of PO-PR distribution of O3-3km over Europe, from IASI+GOME-2 and IASI-NG+UVNS. Real IASI+GOME-2 values of DOF-3km and Hmax-3km are reported in parenthesis below pseudo-real ones.

\begin{tabular}{|c|c|c|c|c|c|c|c|c|}
\hline & \multicolumn{2}{|c|}{ DOF-3km } & \multicolumn{2}{|c|}{ Hmax-3km [km] } & \multirow[t]{2}{*}{$R$} & \multirow{2}{*}{$\begin{array}{r}\text { Bias } \\
{[\mathrm{DU}]}\end{array}$} & \multirow{2}{*}{$\begin{array}{r}\sigma-\text { bias } \\
{[\mathrm{DU}]}\end{array}$} & \multirow{2}{*}{$\begin{array}{r}\mathrm{Rms} \\
{[\mathrm{DU}]}\end{array}$} \\
\hline & land & ocean & land & ocean & & & & \\
\hline $\begin{array}{l}\text { IASI+GOME-2 } \\
\text { (real) }\end{array}$ & $\begin{array}{r}0.29 \pm 0.06 \\
(0.29 \pm 0.08)\end{array}$ & $\begin{array}{r}0.21 \pm 0.06 \\
(0.21 \pm 0.08)\end{array}$ & $\begin{array}{r}2.46 \pm 0.60 \\
(2.51 \pm 0.88)\end{array}$ & $\begin{array}{r}3.39 \pm 0.68 \\
(3.32 \pm 1.07)\end{array}$ & 0.65 & -1.30 & 1.79 & 1.77 \\
\hline $\begin{array}{l}\text { IASI-NG+UVNS } \\
\text { gain }\end{array}$ & $\begin{array}{r}0.75 \pm 0.19 \\
+159 \%\end{array}$ & $\begin{array}{r}0.66 \pm 0.15 \\
+214 \%\end{array}$ & $\begin{array}{r}1.43 \pm 0.50 \\
-1.03\end{array}$ & $\begin{array}{r}2.09 \pm 0.60 \\
-1.30\end{array}$ & $\begin{array}{r}0.73 \\
+12 \%\end{array}$ & $\begin{array}{l}-1.01 \\
-22 \%\end{array}$ & $\begin{array}{r}1.70 \\
-5 \%\end{array}$ & $\begin{array}{r}1.55 \\
-12 \%\end{array}$ \\
\hline
\end{tabular}

\subsection{Capacity of resolving layers}

Along with sensitivity to surface ozone concentrations, vertical resolution of ozone retrievals is the major limitation of such products. Indeed, the mixing of vertical information screens out the origin of ozone and limits, for example, their ability to improve models when assimilated.

Figure 9 shows a transect of ozone profiles which allows one to compare the capability of each retrieval to resolve ozone layers. It presents the vertical cross sections of ozone concentration as observed by IASI+GOME-2 (top) and IASI-NG+UVNS (middle), with the corresponding MOCAGE output (bottom). Data are averaged horizontally with a resolution of $1 \times 1^{\circ}$, along the latitude band $\left[38,39^{\circ} \mathrm{N}\right]$. Both retrieval methods show an overall agreement with pseudo-reality for ozone plumes with concentration higher than 1.0 molecules $\mu \mathrm{m}^{-3}$.

The comparison of the IASI+GOME- 2 cross section with the pseudo-real $\mathrm{O}_{3}$ concentration confirms that IASI+GOME-2 is able to resolve complex vertical ozone distribution in the lowermost and lower troposphere. This is true for the three ozone peaks (red colour) at $\left[14,10^{\circ} \mathrm{W}\right]$, $\left[4,8^{\circ} \mathrm{E}\right]$ and $\left[20,30^{\circ} \mathrm{E}\right]$ or the moderate $\mathrm{O}_{3}$ concentrations (yellow-green colour) at $\left[12^{\circ} \mathrm{W}, 5^{\circ} \mathrm{E}\right]$ and $\left[9,17^{\circ} \mathrm{E}\right]$ located below a clean atmosphere. The vertical structures described by IASI+GOME-2 matches well with MOCAGE simulations and are consistent with the real IASI+GOME-2 product, which is able to observe ozone plumes below $3 \mathrm{~km}$, even if it cannot distinguish whether the ozone plumes are located in the LMT or between 3 and $6 \mathrm{~km}$ altitude (Cuesta et al., 2013).

IASI-NG+UVNS shows a finer resolution than IASI+GOME-2, resolving ozone layers of 2-3 km thickness below $3 \mathrm{~km}$ altitude. At $\left[0,5^{\circ} \mathrm{E}\right]$ and $\left[8,20^{\circ} \mathrm{E}\right]$, ozone concentrations higher than 1.2 molecules $\mu \mathrm{m}^{-3}$ are entirely located in the lowermost troposphere. Even if partially, IASI-NG+UVNS is able to detect the presence of LMT ozone whereas IASI+GOME-2 fails to detect strong $\mathrm{O}_{3}$ concentrations.

Same as Fig. 9, but for the 11 July 2010, Fig. 10 shows the $\mathrm{O} 3-3 \mathrm{~km}$ vertical cross section in the $\left[38,39^{\circ} \mathrm{N}\right]$ lat- itude band. Again, IASI-NG+UVNS provides more reliable retrievals where ozone concentrations are larger than 1.2 molecules $\mu \mathrm{m}^{-3}$, such as at $\left[3,10^{\circ} \mathrm{E}\right]$ below $4 \mathrm{~km}$ (and in particular the peak at $\left[8^{\circ} \mathrm{E}, 10^{\circ} \mathrm{E}\right]$ below $2 \mathrm{~km}$ ) and at $\left[14,19^{\circ} \mathrm{E}\right]$ below $3 \mathrm{~km}$. At higher altitudes between 11 and $13 \mathrm{~km}$ a.s.l., the $2 \mathrm{~km}$ thick ozone layer at $\left[12,20^{\circ} \mathrm{E}\right]$ is well resolved by IASI-NG+UVNS but invisible to IASI+GOME2.

The ability of IASI-NG+UVNS to identify ozone gradient between the $3-6 \mathrm{~km}$ and the surface- $3 \mathrm{~km}$ layers is analysed afterwards. Figure 11 shows maps of pixel-by-pixel difference in ozone partial columns between the two altitude bands. Negative values (in purple) indicate where the $\mathrm{O}_{3}$ concentration is higher in the LMT. The regional standard deviation of the difference is reported in the figure, above the colour scale. IASI-NG+UVNS (middle) clearly shows a better agreement with pseudo-reality (bottom) than IASI+GOME-2 (top), especially over northern France, the Netherlands and the Mediterranean basin.

The same data set shown in Fig. 11 is analysed in Fig. 12 as a scatter plot. On the $y$ axis we present pseudo-observations, plotted as a function of pseudo-reality (black) and AVKsmoothed pseudo-reality (red). Both methods seem to correctly identify those cases where pseudo-real differences are positive, but IASI-NG+UVNS also allows the detection of negative values (higher ozone concentration in the LMT than above it) down to $-8 \mathrm{DU}$, while IASI+GOME-2 is limited to -2 DU. In case of EPS-SG sensors, the mean error between pseudo-reality and synthetic retrievals is sensibly less biased by $-36 \%$. At the same time, IASI-NG+UVNS shows a larger dispersion in the scatter plot of POs versus PR $\times$ AVK, because of a larger measurement error than IASI+GOME-2 (although total error remains similar in both cases).

\section{Summary and conclusion}

In this work, we quantify the potential of the synergism for LMT ozone retrieval by combining TIR and UV measurements from the new-generation sensors IASI-NG and UVNS (on board the EPS-SG satellite) with respect to the existing IASI+GOME-2 multispectral method. To achieve this 
goal, we develop a pseudo-observation simulator. The nature run is generated by the MOCAGE model, where real ozone data from surface network stations, and IASI and MLS instruments have been assimilated for a realistic representation of ozone horizontal variability at the surface and the free troposphere. To ensure the highest degree of reliability with respect to the experiment, the pseudo-real atmosphere has been carefully calibrated by a comparison of real data with the POS of IASI+GOME-2. Cloud fraction, skin temperature and temperature profile were empirically corrected in order to obtain realistic sensitivity values of the satellite products. This calibration stage of meteorological variables, which are important for the retrievals, appears to be a key point of the methodology and we believe it should systematically be considered in OSSEs. Atmospheric and surface spectra are simulated by KOPRA and VLIDORT radiative transfer codes, performing full and accurate forward and inverse radiative transfer calculations. We analyse and compare pseudo-observations from IASI+GOME-2 and IASING+UVNS for 8-11 July 2010 over Europe. Data assimilation analysis in a different chemical transport model independent from MOCAGE is left to future research work.

Over the whole time period, IASI-NG+UVNS estimates of ozone partial columns, calculated between the surface and $3 \mathrm{~km}$ altitude, are highly correlated to the MOCAGE outputs. With respect to IASI+GOME-2, using new-generation sensors the correlation coefficient between $03-3 \mathrm{~km}$ pseudoobservations and pseudo-reality increases on average by about $12 \%$, from 0.65 to 0.73 , and the retrieval of high ozone values is less underestimated. As a consequence, the retrieval bias is significantly reduced by $-22 \%$, while $\sigma$-bias slightly decreases by $-5 \%$. The bias between PO and PR gives an estimate of the retrieval method accuracy. It is strongly improved, mostly because of a higher retrieval sensitivity to true profiles in the lower tropospheric layers (below $2-3 \mathrm{~km}$ ). The $\sigma$-bias quantifies the total error of the multispectral retrieval and measures the inversion algorithm precision that remains almost constant when migrating from the existing to the newgeneration sensor synergism.

The focus of IASI-NG+UVNS retrieval algorithm parametrization has been to optimize the sensitivity in the lowest layers of the atmosphere, rather than decreasing the total retrieval error. Hence, the major gain of using the multispectral synergism of EPS-SG sensors with our retrieval approach concerns DOF- $3 \mathrm{~km}$ and Hmax- $3 \mathrm{~km}$. With respect to IASI+GOME-2, the mean DOF-3km of IASI-NG+UVNS increases over both land (from 0.29 to 0.75 ) and ocean (from 0.21 to 0.66 ), which are respectively 159 and $214 \%$ higher than using present instrumentation. Accordingly, the mean height of maximum sensitivity in the LMT decreases down to $1.43 \mathrm{~km}$ over land and $2.09 \mathrm{~km}$ over ocean, which is approximately 1.03 and $1.30 \mathrm{~km}$ below that of IASI+GOME-2. In addition, IASI-NG+UVNS can also provide reliable ozone retrievals below $2 \mathrm{~km}$ altitude, with an average DOF- $2 \mathrm{~km}$ of 0.52 (land) and 0.42 (ocean) and a mean Hmax-2km of 1.29 (land) and $1.96 \mathrm{~km}$ (ocean). It seems to be able to observe ozone layers of $2-3 \mathrm{~km}$ thickness and distinguish whether ozone plumes are located in the lowermost troposphere or just above it, between 3 and $6 \mathrm{~km}$.

It is worth noting that an additional challenge will be encountered for real retrievals using high SNR spectra from IASI-NG and UVNS. Indeed, as noise will be lower for such measurements, new sources of errors will be significant (i.e. surface properties accuracy, trace gasses variability). Such additional errors are not considered here and might degrade the capability of the retrieval. Results presented here are then an upper limit of the capability expected for IASING+UVNS multispectral synergism to probe ozone pollution.

Nevertheless, IASI-NG+UVNS shows a unique ability to provide high-confidence $\mathrm{O}_{3}$ retrievals in the first $2-3 \mathrm{~km}$ of the atmosphere that should significantly improve regional ozone estimates for air quality studies. Further work should assess the potential impact on ozone forecasts when assimilating this new multispectral product in a chemical transport model independent from MOCAGE.

Data availability. Pseudo-retrievals from IASI+GOME-2 and IASI-NG+UVNS multispectral algorithms and MOCAGE model simulation outputs used here can be requested upon demand from juan.cuesta@lisa.u-pec.fr. From 2017, real IASI+GOME2 ozone retrievals are available at the AERIS data centre at http://www. aeris-data.fr.

Competing interests. The authors declare that they have no conflict of interest.

Acknowledgements. The authors are grateful for the financial support given by the Centre National des Études Spatiales (CNES, the French Space Agency), the Université Paris Est Créteil (UPEC), the Centre National des Recherches Scientifiques - Institut National des Sciences de l'Univers (CNRS-INSU). This study was financed by the project SURVEYOZON-TOSCA (Terre, Oceìan, Surfaces Continentales, Atmosphère) from CNES. We acknowledge the support by the data center ETHER (http://www.pole-ether.fr), ICARE (http://www.icare.univ-lille1.fr), and NOAA (https://www.class.ncdc.noaa.) for providing respectively data sets from IASI (level 1C, originally supplied by EUMETSAT through the EUMETCast system distribution, http://www.eumetsat.int) and GOME-2 (level 1B). Meteorological reanalyses are produced by ECMWF and supplied by CLIMSERV (http://climserv.ipsl.polytechnique.fr). We also thank Joerg Langen from the ESA for providing us with detailed information on UVNS (Sentinel-5) technical specifications.

Edited by: H. Worden

Reviewed by: two anonymous referees 


\section{References}

Amann, M., Bertok, I., Cofala, J., Gyarfas, F., Heyes, C., Klimont, Z., Schoepp, W. and Winiwarter, W.:Baseline Scenarios for the Clean Air for Europe (CAFE) Programme, Final report for the study on Development of the Baseline and Policy Scenarios and Integrated Assessment Modelling Framework for the Clean Air for Europe (CAFE) Programme-Lot 1, 2005.

Barret, B., Le Flochmoen, E., Sauvage, B., Pavelin, E., Matricardi, M., and Cammas, J. P.: The detection of post-monsoon tropospheric ozone variability over south Asia using IASI data, Atmos. Chem. Phys., 11, 9533-9548, doi:10.5194/acp-11-95332011, 2011.

Cai, Z., Liu, Y., Liu, X., Chance, K., Nowlan, C. R., Lang, R., Munro, R., and Suleiman, R.: Characterization and correction of Global Ozone Monitoring Experiment 2 ultraviolet measurements and application to ozone profile retrievals, J. Geophys. Res., 117, D07305, doi:10.1029/2011JD017096, 2012.

Claeyman, M., Attié, J.-L., Peuch, V.-H., El Amraoui, L., Lahoz, W. A., Josse, B., Joly, M., Barré, J., Ricaud, P., Massart, S., Piacentini, A., von Clarmann, T., Höpfner, M., Orphal, J., Flaud, J.M., and Edwards, D. P.: A thermal infrared instrument onboard a geostationary platform for $\mathrm{CO}$ and $\mathrm{O} 3$ measurements in the lowermost troposphere: Observing System Simulation Experiments (OSSE), Atmos. Meas. Tech., 4, 1637-1661, doi:10.5194/amt-41637-2011, 2011.

Clerbaux, C., Boynard, A., Clarisse, L., George, M., Hadji-Lazaro, J., Herbin, H., Hurtmans, D., Pommier, M., Razavi, A., Turquety, S., Wespes, C., and Coheur, P.-F.: Monitoring of atmospheric composition using the thermal infrared IASI/MetOp sounder, Atmos. Chem. Phys., 9, 6041-6054, doi:10.5194/acp-9-6041-2009, 2009.

Coman, A., Foret, G., Beekmann, M., Eremenko, M., Dufour, G., Gaubert, B., Ung, A., Schmechtig, C., Flaud, J.-M., and Bergametti, G.: Assimilation of IASI partial tropospheric columns with an Ensemble Kalman Filter over Europe, Atmos. Chem. Phys., 12, 2513-2532, doi:10.5194/acp-12-2513-2012, 2012.

Cuesta, J., Eremenko, M., Liu, X., Dufour, G., Cai, Z., Höpfner, M., von Clarmann, T., Sellitto, P., Foret, G., Gaubert, B., Beekmann, M., Orphal, J., Chance, K., Spurr, R., and Flaud, J.-M.: Satellite observation of lowermost tropospheric ozone by multispectral synergism of IASI thermal infrared and GOME-2 ultraviolet measurements over Europe, Atmos. Chem. Phys., 13, 9675-9693, doi:10.5194/acp-13-9675-2013, 2013.

Dufour, A., Amodei, M., Ancellet, G., and Peuch, V.-H.: Observed and modelled chemical weather during ESCOMPTE, Atmos. Res., 74, 161-189, doi:10.1016/j.atmosres.2004.04.013, 2005.

Dufour, G., Eremenko, M., Orphal, J., and Flaud, J.-M.: IASI observations of seasonal and day-to-day variations of tropospheric ozone over three highly populated areas of China: Beijing, Shanghai, and Hong Kong, Atmos. Chem. Phys., 10, 3787 3801, doi:10.5194/acp-10-3787-2010, 2010.

Edwards, D. P., Arellano Jr., A. F., and Deeter, M. N.: A satellite observation system simulation experiment for carbon monoxide in the lowermost troposphere, J. Geophys. Res., 114, D14304, doi:10.1029/2008JD011375, 2009.

Emili, E., Barret, B., Massart, S., Le Flochmoen, E., Piacentini, A., El Amraoui, L., Pannekoucke, O., and Cariolle, D.: Combined assimilation of IASI and MLS observations to constrain tropospheric and stratospheric ozone in a global chemical transport model, Atmos. Chem. Phys., 14, 177-198, doi:10.5194/acp-14177-2014, 2014

Eremenko, M., Dufour, G., Foret, G., Keim, C., Orphal, J., Beekmann, M., Bergametti, G., and Flaud, J.-M.: Tropospheric ozone distributions over Europe during the heat wave in July $2007 \mathrm{ob}$ served from infrared nadir spectra recorded by IASI, Geophys. Res. Lett., 35, L18805, doi:10.1029/2008GL034803, 2008.

European Organisation for the Exploitation of Meteorological Satellites (EUMETSAT): GOME-2 Level 1 product generation specification, EPS.SYS.SPE.990011, Darmstadt, Germany, 2006.

Foret, G., Eremenko, M., Cuesta, J., Sellitto, P., Barré, J., Gaubert, B., Coman, A., Dufour, G., Liu, X., Joly, M., Doche, C., and Beekmann, M.: Ozone pollution: What can we see from space? A case study, J. Geophys. Res.-Atmos., 119, 8476-8499, doi:10.1002/2013JD021340, 2014.

Fu, D., Worden, J. R., Liu, X., Kulawik, S. S., Bowman, K. W., and Natraj, V.: Characterization of ozone profiles derived from Aura TES and OMI radiances, Atmos. Chem. Phys., 13, 3445-3462, doi:10.5194/acp-13-3445-2013, 2013.

Jaumouillé, E., Massart, S., Piacentini, A., Cariolle, D., and Peuch, V.-H.: Impact of a time-dependent background error covariance matrix on air quality analysis, Geosci. Model Dev., 5, 10751090, doi:10.5194/gmd-5-1075-2012, 2012.

Josse, B., Simon, P., and Peuch, V.-H.: Radon global simulations with the multiscale chemistry and transport model MOCAGE, Tellus B, 56, 339-356, 2004.

Koelemeijer, R., Stammes, P., Hovenier, J., and Haan, J. D.: A fast method for retrieval of cloud parameters using oxygen A band measurements from the Global Ozone Monitoring Experiment, J. Geophys. Res., 106, 3475-3490, doi:10.1029/2000JD900657, 2001.

Landgraf, J. and Hasekamp, O. P.: Retrieval of tropospheric ozone: The synergistic use of thermal infrared emission and ultraviolet reflectivity measurements from space, J. Geophys. Res., 112, D08310, doi:10.1029/2006JD008097, 2007.

Liu, X., Bhartia, P. K., Chance, K., Spurr, R. J. D., and Kurosu, T. P.: Ozone profile retrievals from the Ozone Monitoring Instrument, Atmos. Chem. Phys., 10, 2521-2537, doi:10.5194/acp-10-25212010, 2010.

Marécal, V., Peuch, V.-H., Andersson, C., Andersson, S., Arteta, J., Beekmann, M., Benedictow, A., Bergström, R., Bessagnet, B., Cansado, A., Chéroux, F., Colette, A., Coman, A., Curier, R. L., Denier van der Gon, H. A. C., Drouin, A., Elbern, H., Emili, E., Engelen, R. J., Eskes, H. J., Foret, G., Friese, E., Gauss, M., Giannaros, C., Guth, J., Joly, M., Jaumouillé, E., Josse, B., Kadygrov, N., Kaiser, J. W., Krajsek, K., Kuenen, J., Kumar, U., Liora, N., Lopez, E., Malherbe, L., Martinez, I., Melas, D., Meleux, F., Menut, L., Moinat, P., Morales, T., Parmentier, J., Piacentini, A., Plu, M., Poupkou, A., Queguiner, S., Robertson, L., Rouïl, L., Schaap, M., Segers, A., Sofiev, M., Tarasson, L., Thomas, M., Timmermans, R., Valdebenito, Á., van Velthoven, P., van Versendaal, R., Vira, J., and Ung, A.: A regional air quality forecasting system over Europe: the MACC-II daily ensemble production, Geosci. Model Dev., 8, 2777-2813, doi:10.5194/gmd8-2777-2015, 2015.

Masutani, M., Woollen, J. S., Lord, S. J., Emmitt, G. D., Kleespies, T. J., Wood, S. A., Greco, S., Sun, H., Terry, J., Kapoor, V., Treadon, R., and Campana, K. A.: Observ- 
ing system simulation experiments at the National Centers for Environmental Prediction, J. Geophys. Res., 115, D07101, doi:10.1029/2009JD012528, 2010.

McPeters, R. D., Labow, G. J., and Logan, J. A.: Ozone climatological profiles for satellite retrieval algorithms, J. Geophys. Res., 112, D05308, doi:10.1029/2005JD006823, 2007.

Nowlan, C. R., Liu, X., Chance, K., Cai, Z., Kurosu, T. P., Lee, C., and Martin, R. V.: Retrievals of sulfur dioxide from the Global Ozone Monitoring Experiment 2 (GOME-2) using an optimal estimation approach: Algorithm and initial validation, J. Geophys. Res., 116, D18301, doi:10.1029/2011JD015808, 2011.

Rodgers, C. D.: Inverse methods for atmospheric sounding: Theory and practice, World Scientific Publishing Company, London, UK, 200 pp., 2000.

Sellitto, P., Dufour, G., Eremenko, M., Cuesta, J., Peuch, V.-H., Eldering, A., Edwards, D. P., and Flaud, J.-M.: The effect of using limited scene-dependent averaging kernels approximations for the implementation of fast observing system simulation experiments targeted on lower tropospheric ozone, Atmos. Meas. Tech., 6, 1869-1881, doi:10.5194/amt-6-1869-2013, 2013.

Worden, H. M., Edwards, D. P., Deeter, M. N., Fu, D., Kulawik, S. S., Worden, J. R., and Arellano, A.: Averaging kernel prediction from atmospheric and surface state parameters based on multiple regression for nadir-viewing satellite measurements of carbon monoxide and ozone, Atmos. Meas. Tech., 6, 1633-1646, doi:10.5194/amt-6-1633-2013, 2013.
Worden, J., Liu, X., Bowman, K., Chance, K., Beer, R., Eldering, A., Gunson, M., and Worden, H.: Improved tropospheric ozone profile retrievals using OMI and TES radiances, Geophys. Res. Lett., 34, L01809, doi:10.1029/2006GL027806, 2007.

Zoogman, P., Jacob, D. J., Chance, K., Zhang, L., Sager, P. L., Fiore, A. M., Eldering, A., Liu, X., Natraj, V., and Kulawik, S. S.: Ozone air quality measurement requirements for a geostationary satellite mission, Atmos. Environ., 45, 7143-7150, doi:10.1016/j.atmosenv.2011.05.058, 2011.

Zyryanov, D., Foret, G., Eremenko, M., Beekmann, M., Cammas, J.-P., D'Isidoro, M., Elbern, H., Flemming, J., Friese, E., Kioutsioutkis, I., Maurizi, A., Melas, D., Meleux, F., Menut, L., Moinat, P., Peuch, V.-H., Poupkou, A., Razinger, M., Schultz, M., Stein, O., Suttie, A. M., Valdebenito, A., Zerefos, C., Dufour, G., Bergametti, G., and Flaud, J.-M.: 3-D evaluation of tropospheric ozone simulations by an ensemble of regional Chemistry Transport Model, Atmos. Chem. Phys., 12, 3219-3240, doi:10.5194/acp-12-3219-2012, 2012. 